\title{
Article \\ Expression Patterns of DNA Methylation and Demethylation Genes during Plant Development and in Response to Phytohormones
}

\author{
Morgan Bennett, Kailyn Cleaves and Tarek Hewezi * \\ Department of Plant Sciences, University of Tennessee, Knoxville, TN 37996, USA; \\ mmbennet@vols.utk.edu (M.B.); kcleave1@vols.utk.edu (K.C.) \\ * Correspondence: thewezi@utk.edu
}

Citation: Bennett, M.; Cleaves, K.; Hewezi, T. Expression Patterns of DNA Methylation and

Demethylation Genes during Plant Development and in Response to Phytohormones. Int. J. Mol. Sci. 2021, 22, 9681. https://doi.org/10.3390/ ijms22189681

Academic Editor: Raul Pirona

Received: 2 August 2021

Accepted: 6 September 2021

Published: 7 September 2021

Publisher's Note: MDPI stays neutral with regard to jurisdictional claims in published maps and institutional affiliations.

Copyright: (C) 2021 by the authors. Licensee MDPI, Basel, Switzerland. This article is an open access article distributed under the terms and conditions of the Creative Commons Attribution (CC BY) license (https:// creativecommons.org/licenses/by/ $4.0 /)$.

\begin{abstract}
DNA methylation and demethylation precisely and effectively modulate gene expression during plant growth and development and in response to stress. However, expression profiles of genes involved in DNA methylation and demethylation during plant development and their responses to phytohormone treatments remain largely unknown. We characterized the spatiotemporal expression patterns of genes involved in de novo methylation, methyl maintenance, and active demethylation in roots, shoots, and reproductive organs using $\beta$-glucuronidase (GUS) reporter lines. Promoters of DNA demethylases were generally more highly active at the mature root tissues, whereas the promoters of genes involved in DNA methylation were more highly active at fast-growing root tissues. The promoter activity also implies that methylation status in shoot apex, leaf primordia, floral organs, and developing embryos is under tight equilibrium through the activity of genes involved in DNA methylation and demethylation. The promoter activity of DNA methylation and demethylation-related genes in response to various phytohormone treatments revealed that phytohormones can alter DNA methylation status in specific and redundant ways. Overall, our results illustrate that DNA methylation and demethylation pathways act synergistically and antagonistically in various tissues and in response to phytohormone treatments and point to the existence of hormone-linked methylome regulation mechanisms that may contribute to tissue differentiation and development.
\end{abstract}

Keywords: Arabidopsis; DNA demethylases; DNA methyltransferases; embryogenesis; GUS activity; plant growth and development; phytohormones

\section{Introduction}

Epigenetic mechanisms coordinate the expression of thousands of genes in a heritable yet flexible manner, without changing the underlying DNA sequence [1]. DNA methylation, along with histone modifications, chromatin remodeling, and non-coding small RNAs (sRNAs) constitute the highly dynamic and interconnected epigenome, which contributes to the regulation of gene expression during plant development and stress response [2-9]. DNA methylation is also involved in transposable element (TE) regulation, reproduction, genomic imprinting, intercellular communication, interallelic communication, and genome interactions [5]. DNA methylation is generally regarded as a repressive mark of gene expression. DNA methylation in the promoter of protein coding and microRNA genes has been generally shown to cause transcriptional repression, although recent reports point to a possible role of DNA methylation in gene transcriptional activation [3,10-13]. The functional role of DNA methylation in gene body regions, however, remains largely unknown even though recent studies associate DNA methylation levels and patterns with gene expression and splicing efficiency [14-16].

DNA methylation is the addition of a methyl group to the $\mathrm{C} 5$ position of cytosine and occurs in the $\mathrm{CG}, \mathrm{CHG}$, and $\mathrm{CHH}$ sequence contexts (where $\mathrm{H}$ is any nucleotide except 
G) [17]. In Arabidopsis, the de novo formation of 5-methylcytosine $(5 \mathrm{mC})$ is catalyzed by DNA methyltransferases domains rearranged methyltransferase (DRM1), DRM2, and DRM3 through the RNA-directed DNA methylation (RdDM) pathway, with DRM2 being the key enzyme in this pathway [18-20].

DNA methylation is maintained by distinct sequence context-dependent enzymes following DNA replication and cell division [21]. Methylation in the CG context is maintained by methyltransferase 1 (MET1) [22]. There is also evidence that MET1 paralogs MET2b and MET3 contribute to the maintenance of CG methylation [23]. Variant in methylation1 (VIM1), VIM2, and VIM3 and the heterochromatin-remodeling component decrease in DNA methylation (DDM1) are also considered important factors for CG DNA methylation [24-26]. CHG methylation is maintained by chromomethylase2 (CMT2) and CMT3 [27]. Kryptonite (KYP/SUVH4) and the histone methyltransferase SUVH5 and SUVH6 also contribute to the maintenance of CHG sites [27,28]. For $\mathrm{CHH}$ methylation, CMT2 maintains DNA methylation within pericentromeric long TEs, whereas the RdDM pathway is employed for the maintenance of $\mathrm{CHH}$ methylation at other loci $[24,29]$. The catalytically mutated paralog DRM3 is required for de novo methylation and maintenance of methylated CHH loci at repetitive sequences [20,30]. In addition, CMT1 and DRM1/2 also participate in the maintenance of non-CG methylation [27-29].

As with any balanced system, active DNA demethylation is an equally important epigenetic process for controlling genome-wide methylation levels [31-35]. In Arabidopsis, four DNA demethylase paralogs have been identified for active DNA demethylation: repressor of silencing1 (ROS1), demeter (DME), DME-like2 (DML2) and DML3 [31,33,36-39]. These DNA demethylases remove methylated cytosines through the base excision repair (BER) mechanism and replace them with an unmethylated cytosine [40]. Experimental evidences indicate that DNA methylation and active DNA demethylation are highly synchronized [41,42]. ROS1 is tightly controlled by the methylation level of an RdDM target sequence upstream of the transcriptional start site, called a DNA methylation monitoring sequence (MEMS). MEMS is hypermethylated when cellular RdDM increases or DNA demethylation decreases. MEMS methylation upregulates ROS1, thereby activating DNA demethylation [41].

DNA methylation-mediated transcriptional reprogramming has been reported in various plant developmental processes, from gametogenesis to fruit ripening. Local and global DNA methylation and demethylation are also heavily involved in plant responses to environmental stimuli, including biotic [7,43-45] and abiotic [8,9,46-48] stresses. However, the nature of the biochemical signals that associate with DNA methylome changes during plant development and stress responses are not understood. Phytohormone signaling pathways are involved in almost all aspects of plant growth, development, and stress responses [49-52]. Because phytohormones, similar to epigenetic modifications, are regulated in a special and temporal manner and have the ability to provide plants with regulatory mechanisms to quickly adapt to their biotic and abiotic environments, several studies point to a role for phytohormone signaling in controlling epigenetic pathways [53-56]. However, direct experimental evidence showing the functional relationship between phytohormones and epigenetic modifications remains lacking.

Many orthologous DNA methyltransferases and demethylases have been identified in non-model plant species as well as evolutionary unrelated organisms including invertebrates, humans, and other mammals. Thus, DNA methylation pathways are thought to be conserved and functionally significant. DNA methylation has long been recognized as a critical component of gene regulation, biochemical and hormonal balance, and environmental plasticity [45,57-59]. The expression patterns of individual genes involved in DNA methylation in specific tissues or organs have been previously reported [60-62]. However, comparative analyses of the spatial and temporal expression patterns of key DNA methylation and demethylation-related genes throughout plant growth and development remain missing. In this study, we determined the promoter activity of 15 genes involved in DNA methylation and active DNA demethylation in roots, shoots, and reproductive tissues 
using GUS reporter lines. In order to better understand the connection between DNA methylation and phytohormones, we also assessed the spatiotemporal expression patterns of genes involved in DNA methylation and demethylation in roots and shoots in response to treatment of six phytohormones: auxin (AUX), cytokinin (CK), gibberellic acid (GA), ethylene (ET), abscisic acid (ABA), and salicylic acid (SA). Our results reveal a unique and overlapping expression patterns of these genes in roots, shoots, inflorescences, siliques, and developing seeds, and highlight the importance of DNA methylation-demethylation equilibrium in these tissues. Additionally, our results point to a role of phytohormone signaling in establishing plant methylomes associated with the differentiation and development of various tissues.

\section{Results}

\subsection{Generation of GUS Reporter Lines of 15 DNA Methylation and Demethylation-Related Genes}

In order to assess the spatial and temporal expression patterns of genes involved in DNA methylation and demethylation in various plant tissues and organs, a number of transgenic GUS reporter lines were generated. The 15 selected genes include known cytosine methyltransferases, DNA demethylases (or glycosylases), and other genes required for DNA methylation, all of which are listed in Supplementary Table S1. Each reporter construct expresses GUS under the control of the gene's respective native promoter (i.e., up to approximately $2 \mathrm{~kb}$ upstream of the translation start codon). GUS expression assays were performed and analyzed using at least two independent transgenic lines per construct in two-week-old roots, shoots, and in various reproductive tissues and organs.

\subsection{Promoter Activity of DNA Methylation and Demethylation-Related Genes in Roots}

Several genes involved in DNA methylation, including MET1, CMT1, DRM2, and $D R M 3$, are highly expressed throughout root tissues (Figure 1). The CG methyltransferase MET1 is highly expressed toward the newly grown parts of the root and into the root tips as well as in developing lateral roots (Figure 1A). However, other genes involved in CG methylation, MET2b, MET3, and VIM2 have very limited expression in roots (Figure 1A and Supplementary Figure S1A). VIM1 expression is observed in the tips of main and lateral roots and in the vascular tissues of the newly grown parts of the root (Figure 1A).

Promoter of the de novo methyltransferases DRM2 and DRM3 are strongly active in most of the root tissues, particularly in the newly grown parts of the root and in the root tip, similarly to MET1 (Figure 1B). Thus, it seems likely that DRM2 and DRM3 participate in de novo CG methylation, and MET1 maintains those methylated cytosines following DNA replication in rapidly diving root tissues. While CMT1 is expressed in the majority of root tissues, its expression is mostly towards the mature end of the roots (i.e., towards the shoot) as well as at the base of the lateral roots (Figure 1B). Similar to CMT1, CMT3 is expressed at the mature end of the root, but to a lesser extent (Figure 1B). Therefore, it appears that CMT1 and CMT3 have more specific roles in non-CG methyl maintenance at the mature end of the root tissues. The DNA demethylase ROS1 is expressed exclusively in the root apical meristem (RAM) and in the root caps of the main and auxiliary roots (Figure 1C). $D M E, D M L 2$, and DML3, on the other hand, are expressed throughout the root, with DME being the most highly expressed (Figure 1C). DML2 and DML3 have similar expression patterns, predominantly towards the mature end. These data support the conclusion that DME, DML2, and DML3 have overlapping functions in active DNA demethylation in most parts of the root tissues. Of note is that DDM1, which is required for the maintenance of CG and non-CG methylation [28], is uniquely expressed in the root cap of primary root and lateral root primordia (Figure 1D). 


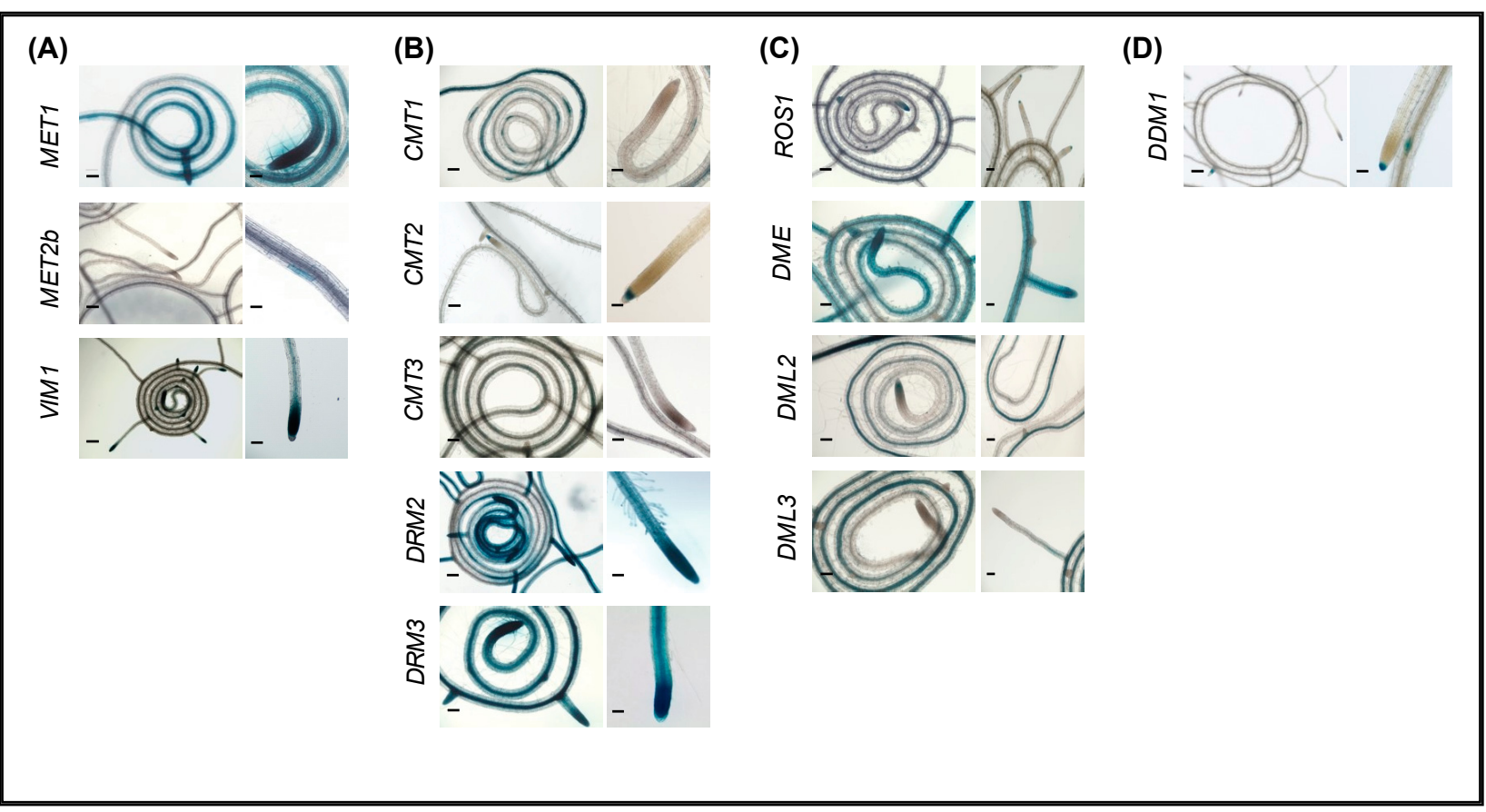

Figure 1. Promoter activity of DNA methylation and demethylation-related genes in two-week-old roots. A-C: Histochemical localization of GUS activity directed by promoters of the CG methylation-related genes MET1, MET2b, and VIM1 (A), the non-CG and RdDM-related methyltransferases CMT1, CMT2, CMT3, DRM2, and DRM3 (B), the demethylases ROS1, $D M E, D M L 2$, and DML3 (C), and DDM1 (D). Scale bar $=5 \mathrm{~mm}$.

\subsection{Promoter Activity of DNA Methylation and Demethylation-Related Genes in Shoots}

GUS staining shows that all tested DNA methyltransferases and demethylases are expressed in the two-week-old shoot tissues (Figure 2). Interestingly, all these genes are transcriptionally active in leaf primordia, suggesting a role for DNA methylationdemethylation equilibrium in leaf morphogenesis. Additionally, the promoter of MET1, MET2b, VIM2, and DDM1 showed activity in the shoot apex (Figure 2A,D). Of the genes involved in DNA methylation, MET1, VIM1, VIM2, CMT1, DRM2, and DRM3 were highly expressed in leaf tissues (Figure 2A,B). VIM1 and VIM2 showed stage-specific expression patterns in leaves, where VIM1 is expressed in mature leaves and VIM2 is expressed in younger tissues (Figure 2A). CMT1 and DRM2 showed distinct expression in leaves. CMT1 is highly expressed in leaf petiole and vascular tissues, whereas DRM2 is expressed in leaf blades but not in the petioles or leaf vascular tissue (Figure 2B). To the contrary, MET1 and $D R M 3$ display expression patterns similar to each other. Both are expressed in leaf blades and in cotyledon vascular tissues (Figure 2A,B), suggesting a coordinated methylation of $\mathrm{CG}$ and $\mathrm{CHH}$ loci in these tissues.

Notably, ROS1, DME, and DML2 appear to be the most highly active genes in leaf primordia (Figure 2C), suggesting that DNA demethylation plays an important role during the early stages of leaf differentiation and development. The DNA demethylases ROS1, $D M E$, and DML2 are highly expressed in shoots (Figure 2C). ROS1 and DML2 are strongly expressed, particularly in young leaves. $D M E$, on the other hand, is highly expressed in leaves, cotyledons, and trichomes, irrespective of leaf developmental stage. These data suggest that DME contribute to active DNA demethylation throughout leaf and cotyledon development and that ROS1 and DML2 contribute to this process only during the early stages of leaf development. The localized expression patterns of DML3 at the tips of leaves and cotyledons suggest its contribution to active DNA demethylation, specifically in these regions. 


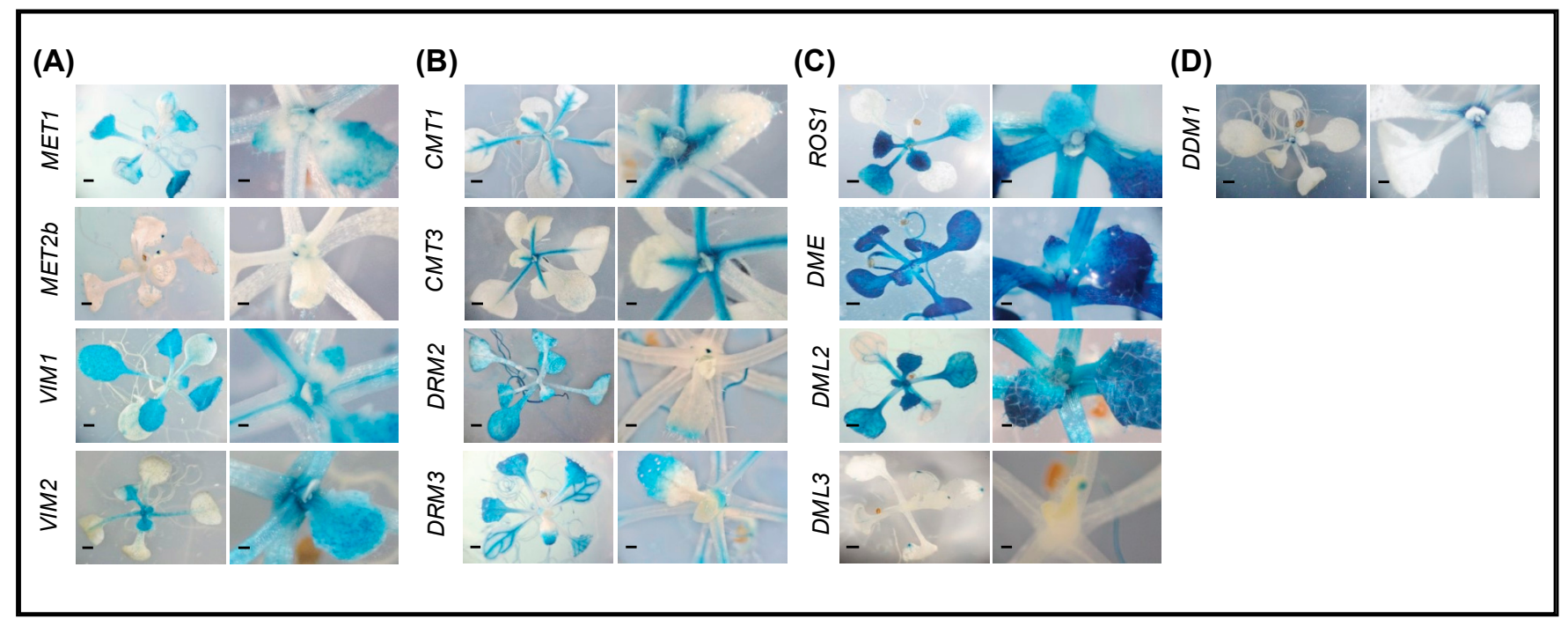

Figure 2. Promoter activity of DNA methylation and demethylation-related genes in two-week-old shoots. A-C: Histochemical localization of GUS activity directed by the promoters of the CG methylation-related genes MET1, MET2b, VIM1, and VIM2 (A), the non-CG and RdDM-related methyltransferases CMT1, CMT3, DRM2, and DRM3 (B), the demethylases ROS1, DME, DML2, and DML3 (C), and DDM1 (D). Scale bar $=5 \mathrm{~mm}$.

\subsection{Promoter Activity of DNA Methylation and Demethylation in Reproductive Tissues \\ 2.4.1. Buds and Open Flowers}

GUS activity reveals that several genes involved in DNA methylation and demethylation are expressed in open flowers and buds (Figure 3A,B). Of the tested genes, only the CG methyltransferase MET1 was expressed in unopened floral buds. MET1, VIM1, DRM2, $D R M 3, D M E$, and ROS1 are expressed in various tissues of open flowers. Remarkably, $D R M 2$ and $D M E$ showed strong expression in petals, anthers, and stigma, suggesting a role for these two enzymes in DNA methylation fine-tuning during flower development (Figure 3B,C). ROS1 is expressed in filaments, suggesting a unique role for DNA demethylation in this structure (Figure 3C). In addition to MET1, DRM2, DRM3, and DME are highly expressed in anthers (Figure 3A-C), reinforcing the hypothesis that DRM2 functions in parallel with DRM3 in RdDM pathways $[20,30,63]$. Taken together, these results demonstrate that DNA methylation and demethylation pathways are active during flowering and fertilization.

\subsubsection{Siliques}

DNA methylation and demethylation pathways are particularly active in the junction between the silique and the pedicel (Figure 3). This region is composed of the gynophore, nectaries, and abscission zone and functions in attaching the silique to the pedicel until mature seeds are ready for dispersal [64]. In the emerging siliques, VIM1 promoter is active in the pedicel, internode junction, and style (Figure 3A). VIM2 expression is predominant in the pedicel, but distinctly absent from the internode junction (Figure 3A). Based on these results, VIM1 could be involved in the early stages of fruit ripening and pedicel development in association with VIM2.

It was also evident from GUS activity that the genes involved in CG methylation are mostly expressed in early stages of silique development, whereas the genes involved in de novo methylation, non-CG methylation, and DNA demethylation were expressed throughout silique development (Figure 3). Notably, DRM2 and DMR3 appear to have roles in DNA methylation of the distal and proximal ends of mature siliques, respectively. In addition, CMT1 and DRM2 show overlapping expression patterns in the style of mature siliques (Figure $3 \mathrm{~B}$ ). DME is the highest DNA demethylase expressed in mature siliques (Figure 3C). 


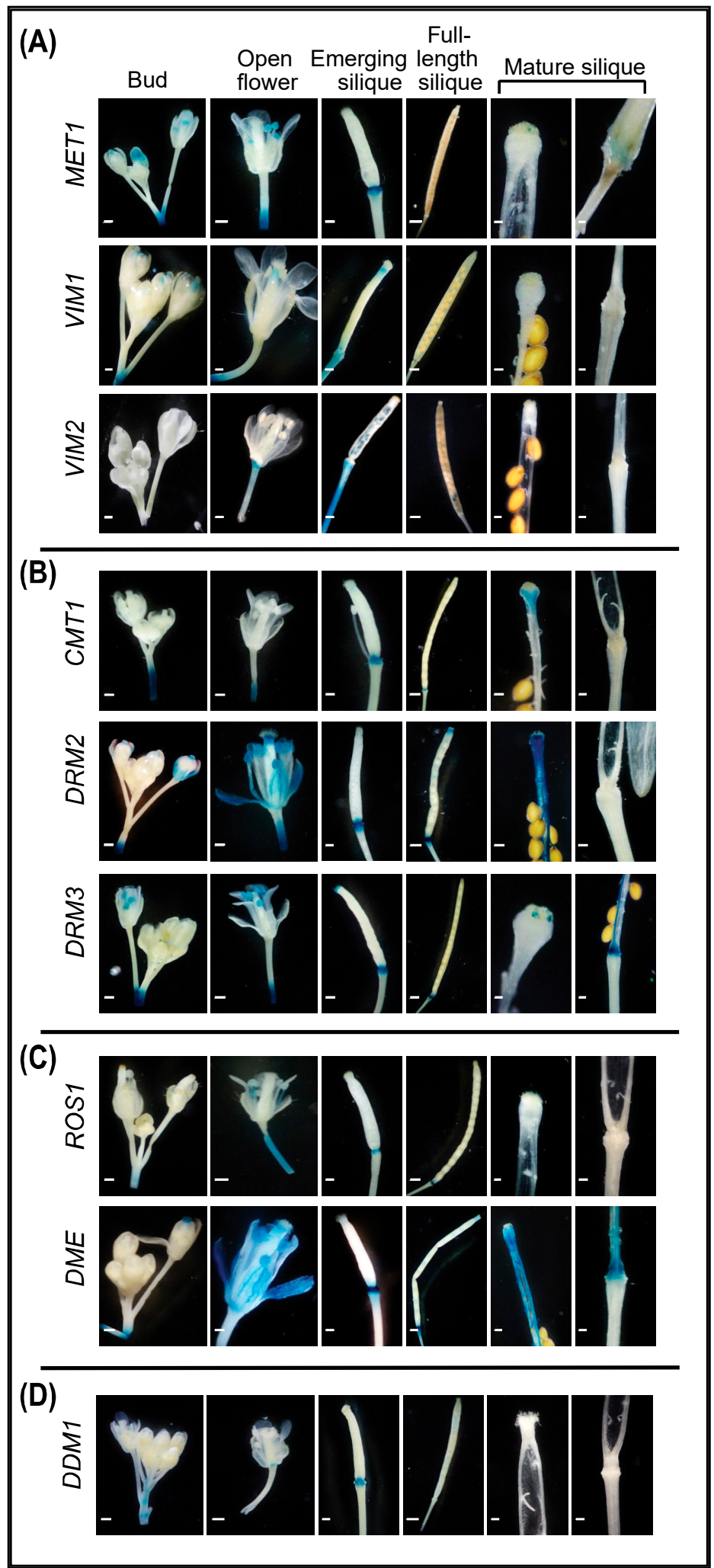

Figure 3. Promoter activity of DNA methylation and demethylation-related genes in floral tissues and organs. A-C: Histochemical localization of GUS activity directed by promoters of the CG methylation-related genes MET1, VIM1, and VIM2 (A), the non-CG and RdDM-related CMT1, DRM2, and DRM3 methyltransferases (B), and the demethylases ROS1 and DME (C), and DDM1 (D) in inflorescence buds, open flowers, emerging siliques, distal end of mature siliques, and proximal end of mature siliques. Scale bar $=5 \mathrm{~mm}$. 


\subsubsection{Seeds}

Our results demonstrate that promoters of many genes involved in DNA methylation and demethylation are also active in developing seeds from the globular to mature stages of embryogenesis. The CG methyltransferases MET1 and MET2b are highly expressed, both in the endosperm and embryo throughout all stages of embryogenesis, whereas MET3 is highly expressed during early embryo developmental stages and decreases with advancement in development (Figure 4A). In contrast to MET3, VIM2 showed increased expression in endosperm and embryo with advancement in development (Figure 4A). VIM1 is expressed exclusively at the globular and heart stages of embryogenesis. However, during the walking-stick and bent-cotyledons embryo stages, the expression of VIM1 was observed both in endosperm and embryonic tissues (Figure 4A).

DRM2 showed high expression, both in endosperm and embryo throughout all embryo developmental stages (Figure 4B), reflecting its role in de novo DNA methylation in all sequence contexts via the RdDM pathway and in maintenance of asymmetric $\mathrm{CHH}$ methylation through persistent de novo methylation during various stages of seed development. CMT1 and CMT2 seem to be expressed in a sequential manner during embryogenesis. While CMT1 is expressed at the globular and heart stages, CMT2 is expressed at the heart, torpedo, and walking-stick stages (Figure 4B). CMT3 was the only gene without detectable expression during embryogenesis under our experimental conditions (Supplementary Figure S1D). DRM3 exhibits specific expression in the elaiosome at all embryo stages. Weak expression of DRM3 was also detected in the embryo and endosperm at the walking-stick and bent-cotyledon stages (Figure 4B).

The DNA demethylases DME and DML3 exhibit strong GUS staining in endosperm and embryo during all embryo developmental stages (Figure 4C). High activity of DML2 promoter was observed during early stages of embryogenesis (globular and heart), and then declined in more advanced embryonic stages (torpedo and walking-stick) (Figure 4C). ROS1 showed the lowest expression among the four DNA demethylases, as its expression was barely detected only at the bent-cotyledon stage (Figure 4C). DDM1 is specifically expressed at the tip of the radical in later stages of embryo development (Figure 4D). Together, these results suggest that embryogenesis and seed development involve dynamic reprogramming of DNA methylation and active demethylation.

\subsection{RNA-seq and RT-qPCR Data Support Promoter Activity of DNA Methylation and Demethylation-Related Genes}

To provide confirmation of our promoter activity data, the gene expression levels of DNA methylation and demethylation-related genes in the root, root tips, leaf, petiole, bud, open flowers, and mature silique of wild-type plants were retrieved from the TraVA RNAseq database [65] and compared with GUS activity. The gene expression levels are generally in agreement with the observed GUS activity of DNA methylation and demethylationrelated genes in various tissues. For example, high expression levels of MET1, DRM3, and DME in root and root tips are in agreement with our data, showing strong GUS activity of these three genes in these tissues (Supplementary Figure S2). Similarly, the high expression levels of ROS1 and DME in leaf and leaf petiole, MET1, VIM1, DRM2, DRM3, and DME, and in buds and open flower, and DME in mature silique, are consistent with GUS activity (Supplementary Figure S2). Additionally, the relative low GUS activity of $M E T 2 b, M E T 3, C M T 1$, and DML3 in various tissues are congruent with RNA-seq data (Supplementary Figure S2). 


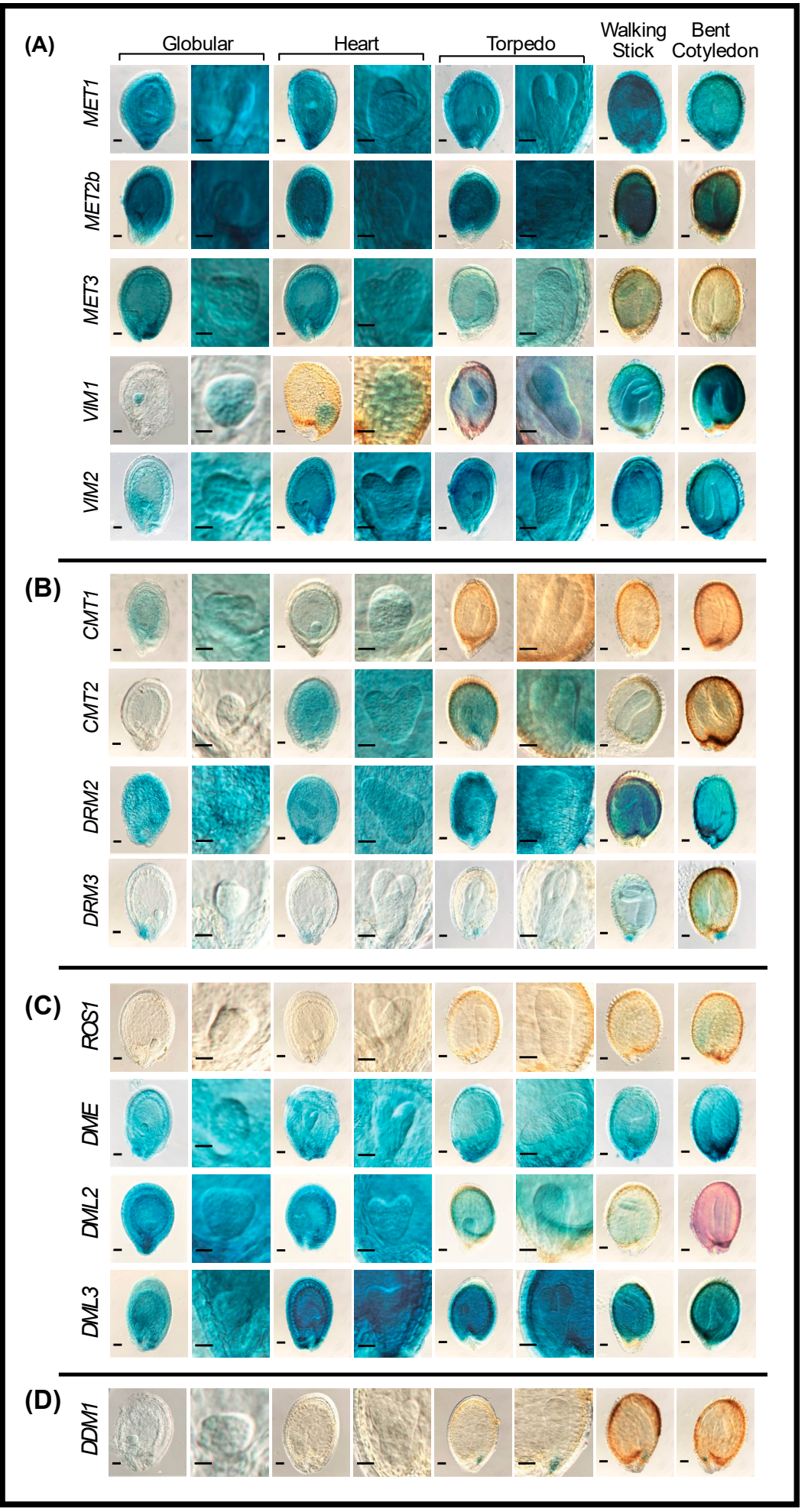

Figure 4. Promoter activity of DNA methylation and demethylation-related genes during various stages of seed development. A-C: Histochemical localization of GUS activity directed by promoters of the CG methylation-related genes MET1, MET2b, MET3, VIM1, and VIM2 (A), the non-CG and RdDM-related methyltransferases CMT1, CMT2, DRM2, and DRM3 (B), the demethylases ROS1, $D M E, D M L 2$, and DML3 (C), and DDM1 (D) at globular, heart, torpedo, walking-stick, and bentcotyledon embryo stages. Scale bar $=5 \mathrm{~mm}$. 
To further validate the GUS activity, we used reverse transcription quantitative PCR (RT-qPCR) to quantify the expression of VIM2, CMT3, and DRM3 in the root tissues of twoweek-old wild-type Col-0 plants. VIM2 showed the lowest expression level, followed by a higher expression of CMT3 (3.75 fold) and DRM3 (7.51 fold) (Supplementary Figure S3A). These expression data are consistent with GUS activity of VIM2, CMT3, and DRM3, which showed no visible, moderate, or high GUS activity in the roots, respectively. Similarly, we measured the expression levels of VIM2, CMT3, and DRM2 in the shoots of two-week-old wild-type Col-0 plants using RT-qPCR. VIM2 showed the lowest expression level followed by higher expression of CMT3 (7.08 fold), and DRM2 (21.24 fold) (Supplementary Figure $\mathrm{S3B})$, confirming the GUS activity of these genes in shoots.

\subsection{Promoter Activity of DNA Methylation and Demethylation-Related Genes in Roots Following Phytohormone Treatments}

We next assessed GUS activity in the roots and shoots of 14-day-old transgenic lines growing on MS medium in response to phytohormone treatments, including auxin (AUX), cytokinin (CK), gibberellic acid (GA), ethylene (ET), abscisic acid (ABA), and salicylic acid (SA). The effectiveness of phytohormone treatments in triggering local and systemic responses in leaves and roots was examined by quantifying the expression levels of marker genes for AUX (auxin response factor19, ARF19), CK (Arabidopsis response regulator 7, ARR7), GA (RGL1), ET (ethylene response2, ETR2), ABA (MYB96), and SA (pathogenesis-related gene1, $P R 1)$ responses [66-68] in phytohormone-treated plants and the corresponding controls $24 \mathrm{~h}$ after phytohormone application using RT-qPCR. Data from three biological replicates revealed significant induction of all these marker genes, both in shoot and root tissues, as compared with the corresponding mock-treated controls (Figure 5A,B), confirming the effectiveness of phytohormone treatments in inducing local and systemic responses.

As shown in Figure 6, SA treatments inhibited the expression of MET1, VIM1, and DRM2. With the exception of DML2, the expression of the DNA demethylases is also inhibited in response to SA application. Thus, SA seems to inhibit DNA methylation and demethylation-related genes alike (Figure 6). ABA treatment enhanced the expression of VIM1 but reduced the expression of DRM3 and DML3 (Figure 6). AUX treatment induced a reduction in the expression of DRM2 and DML3 and slight increase in the expression of CMT3 (Figure 6B,C).

Notably, GA treatment elicited an increase in the expression of DML2 and DML3 (Figure 6C). CK negatively regulated the expression of CMT2 in root tips (Figure 6B). The upregulation of DML2 and DML3 upon GA treatment and their downregulation following SA treatment points to a possible role of active DNA demethylation in establishing the equilibrium between plant growth and defense responses mediated by GA and SA. The expression patterns of MET2b, MET3, and VIM2 did not alter in response to any of the applied hormone treatments (Supplementary Figure S4A). A summary description of changes in the promoter activity of DNA methylation and demethylation-related genes roots in response to various phytohormone treatments is provided in Supplementary Table S2.

\subsection{Promoter Activity of DNA Methylation and Demethylation-Related Gene in Shoots Following Phytohormone Treatments}

As shown in Figure 7, the promoter activity of genes involved in DNA methylation and demethylation were profoundly altered in phytohormone-treated shoots. Exogenous applications of AUX, CK, GA, ET, and ABA inhibited the expression of MET1, VIM2, and DDM1 to various degrees. Notably, GA treatment positively regulated VIM2 (Figure 7A,D). ABA treatment upregulated VIM1, particularly in the cotyledons, and completely suppressed VIM2 in true leaves (Figure 7A). The expression patterns observed for VIM1 and VIM2 in response to ABA and GA treatments suggest that they may play complementary roles in CG methylation, both during development and in response to stress. Overall, genes involved in CG methylation are largely negatively regulated by the phytohormones tested (Figure 7A). 

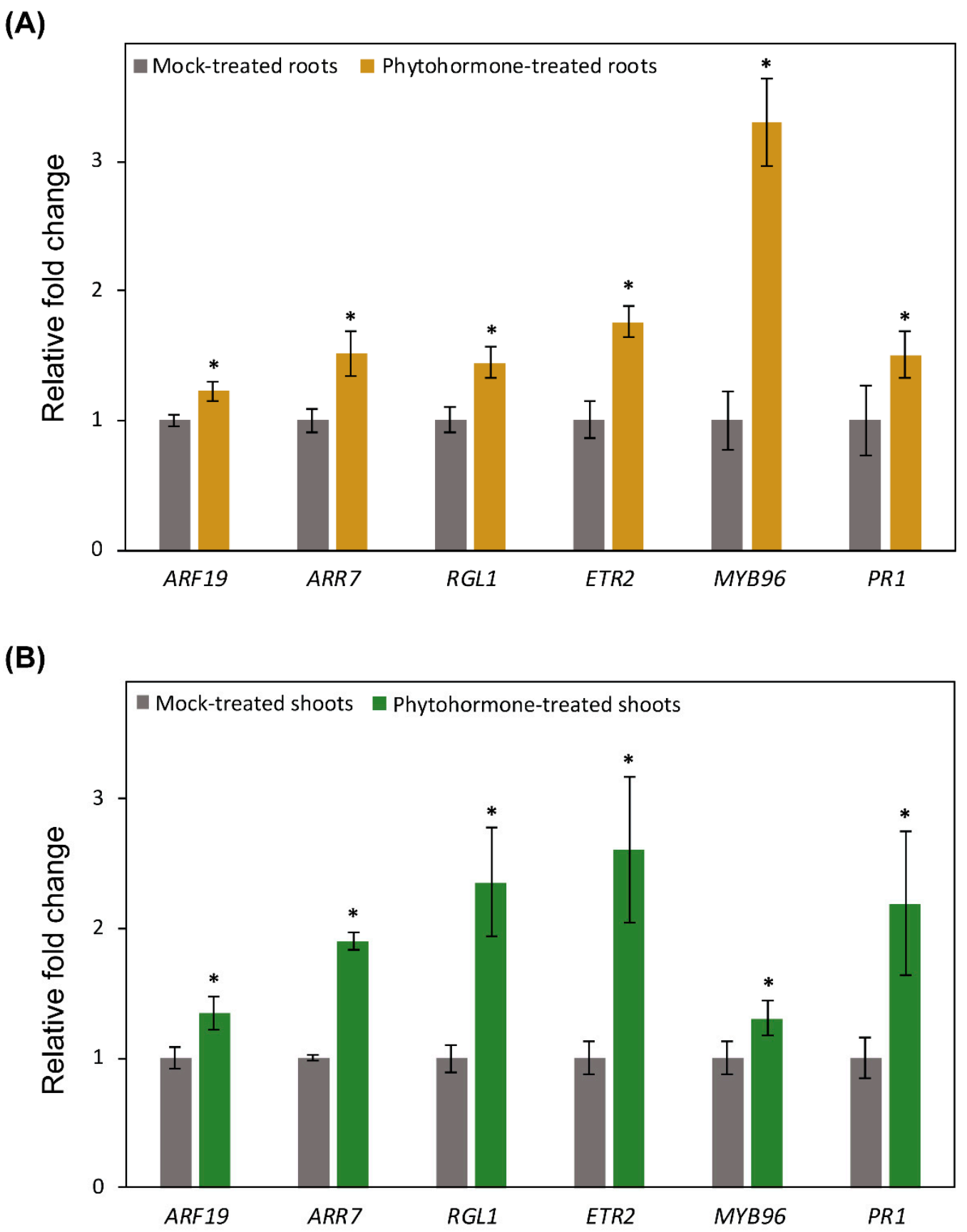

Figure 5. Upregulation of phytohormone marker genes after hormone application. A and B: The expression levels of marker genes for auxin (ARF19), cytokinin (ARR7), gibberellic acid (RGL1), ethylene (ETR2), abscisic aid (MYB96), and salicylic acid (PR1) response were quantified in roots (A) and shoots (B) of treated and control wild-type Col-0 plants $24 \mathrm{~h}$ after hormone application. Relative fold change values were calculated from three biological samples and represent expression in hormone-treated plants relative to mock-treated plants. Actin8 and PP2AA3 were used as internal control to normalize gene expression values. Average CT (cycle threshold) values of Actin 8 and $P P 2 A A 3$ were used to calculated ${ }^{\triangle} \mathrm{CT}$ values and gene expression levels. Asterisks indicate statistically significant differences between hormone-treated and mock-treated plants at $p<0.05$ according to $t$-test. 


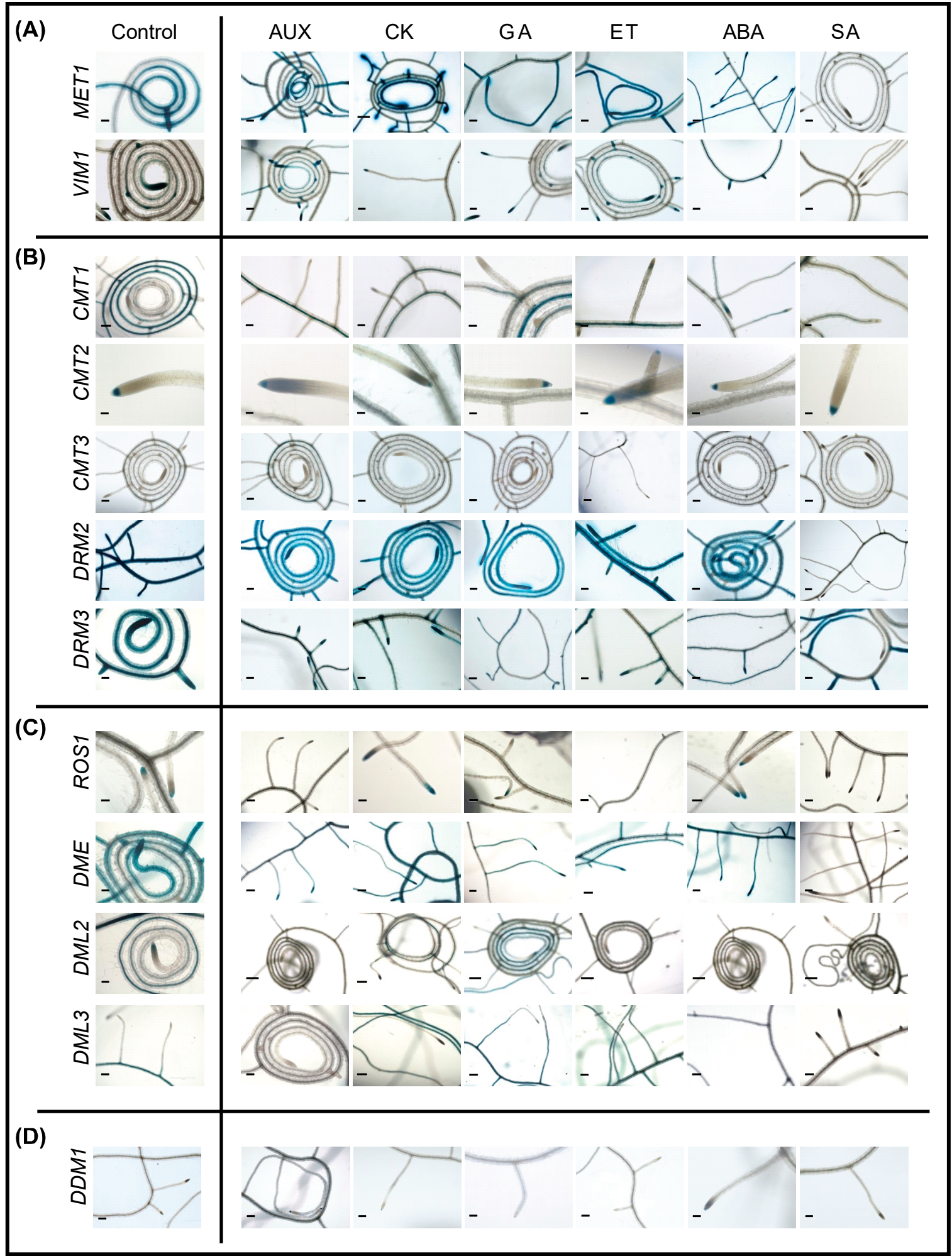

Figure 6. Promoter activity of DNA methylation and demethylation-related genes in two-week-old roots in response to phytohormone treatments. A-C: Histochemical localization of GUS activity directed by promoters of the CG methylationrelated genes MET1 and VIM1 (A), the non-CG and RdDM-related methyltransferases CMT1, CMT2, CMT3, DRM2, and DRM3 (B), the demethylases ROS1, DME, DML2, and DML3 (C), and DDM1 (D) in two-week-old roots in response to exogenous application of auxin (AUX), cytokinin (CK), gibberellic acid (GA), ethylene (ET), abscisic acid (ABA), and salicylic acid (SA). Scale bar $=5 \mathrm{~mm}$. 


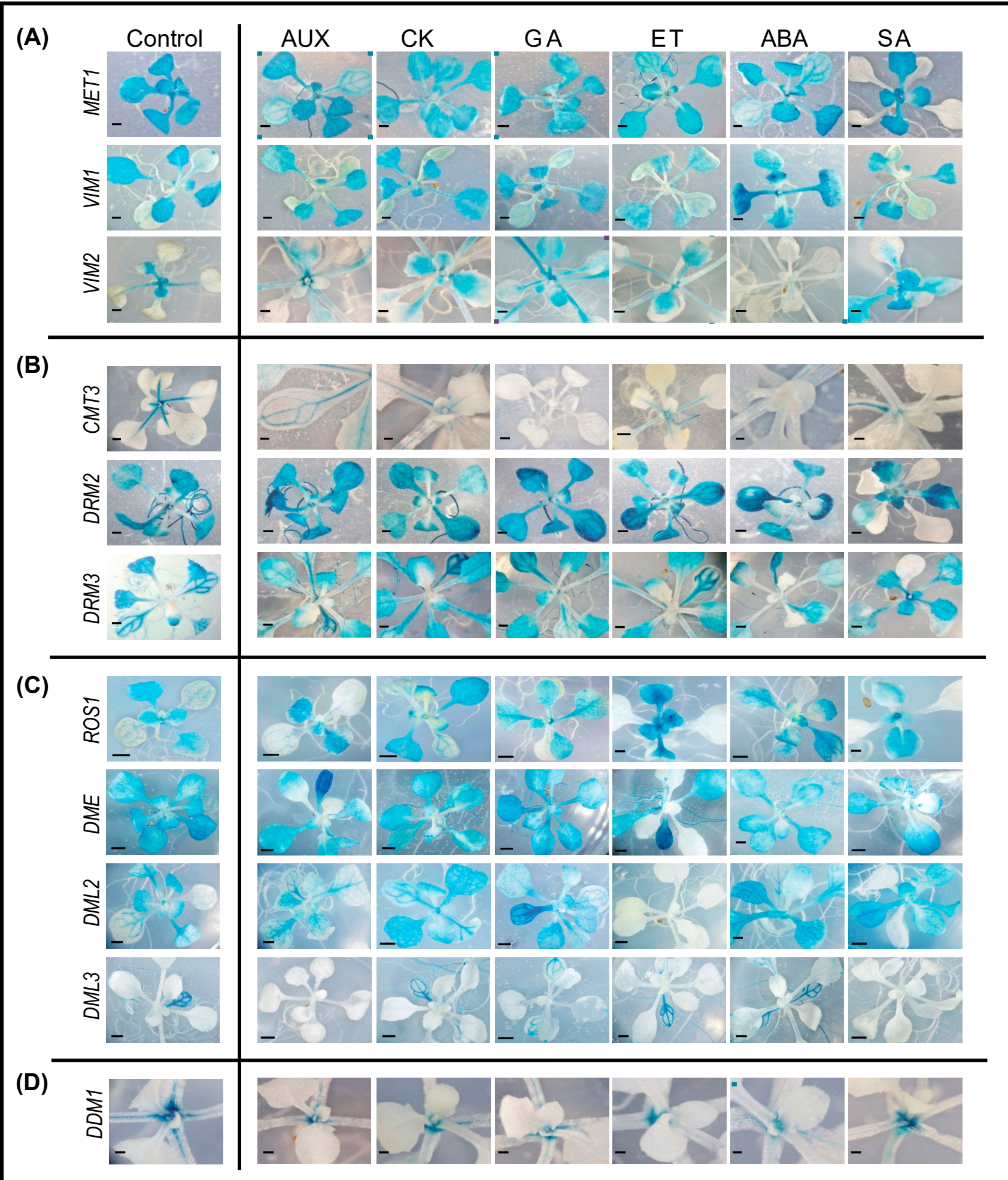

Figure 7. Promoter activity of DNA methylation and demethylation-related genes in two-week-old shoots in response to phytohormone treatments. A-C: Histochemical localization of GUS activity directed by promoters of the CG methylationrelated genes MET1, VIM1, and VIM2 (A), the non-CG and RdDM-related methyltransferases CMT3, DRM2, and DRM3 (B), and the demethylases ROS1, DME, DML2, and DML3 (C), and DDM1 (D) in two-week-old shoots in response to exogenous application of auxin (AUX), cytokinin (CK), gibberellic acid (GA), ethylene (ET), abscisic acid (ABA), and salicylic acid (SA). Scale bar $=5 \mathrm{~mm}$. 
SA treatment negatively impacted MET1 and DDM1 expression, but positively influenced VIM2 expression in leaves (Figure 7A,D). SA and ABA treatments altered the promoter activity of DRM2 and DRM3 in emerging leaves (Figure 7B). In addition to its total suppression of VIM2, ABA treatment also inhibited the expression of CMT3, suggesting that $\mathrm{ABA}$ also regulates components of DNA methylation in two-week old shoots (Figure 7A,B). Furthermore, GA suppressed the expression of CMT3, but enhanced expression of $D R M 2$, giving opposite and complementary expression patterns for these two genes following GA treatment (Figure 7B).

Both ET and AUX treatments reduced DME expression in fast-growing tissues (Figure 7C). Interestingly, the expression of DML2 or DML3 was decreased by ET or AUX, respectively (Figure 7C). In response to ET or AUX treatments, ROS1 appears to be the most responsive DNA demethylase in leaf primordia and young leaves, showing strong GUS activity in these tissues (Figure 7C). SA treatment also impacted DNA demethylation. $D M L 3$ and DME expression was suppressed by SA. In contrast, the expression of ROS1 and DML2 was slightly enhanced in young leaves by SA treatment (Figure 7C). Thus, in general, SA treatment not only inhibits DNA methylation in older leaves, but it also enhances DNA demethylation in fast-growing tissues. The expression patterns of $M E T 2 b$, $M E T 3$, and CMT1 did not alter in response to any of the applied hormone treatments (Supplementary Figure S4B). A summary description of changes in the promoter activity of DNA methylation and demethylation-related genes in response to various phytohormone treatments is provided in Supplementary Table S3.

\subsection{RT-qPCR Data Validate Gene Expression Changes Induced by Phytohormone Treatments}

To validate the gene expression changes of DNA methylation-related genes induced by phytohormone treatments, we used the same RNA samples described in Figure 5 to quantify the expression of genes showing different magnitudes of GUS activity in response to hormone treatments. This includes VIM1 and CMT3 in the root tissues of two-week-old wild-type Col-0 plants upon ABA and AUX application, respectively, as well as DRM2 in the GA-treated roots. The RT-qPCR data of three biological samples revealed two-fold upregulation of VIM1 in ABA-treated roots as compared with mock-treated control roots (Supplementary Figure S5A)). CMT3 expression was increased 7.93-fold in AUX-treated roots as compared with mock-treated roots (Supplementary Figure S5B). Similarly, we quantified the expression of DRM2 in the shoots of two-week-old wild-type Col-0 plants upon GA treatment. The expression levels of DRM2 was increased 3.14-fold in GA-treated shoots as compared with mock-treated shoots (Supplementary Figure S5C). Together, these data support our conclusion that phytohormone treatments induce gene expression changes of DNA methylation-related genes both in roots and shoots.

We next treated 13-day-old plants of the transgenic GUS reporter lines Pro:DML2:GUS, Pro:DRM3:GUS, and Pro:CMT3:GUS with various phytohormone treatments and collected three biological samples of root and shoot tissues $24 \mathrm{~h}$ after application. The expression of GUS and the corresponding endogenous genes were quantified in roots or shoots relative to the corresponding mock-treated transgenic plants. These reporter lines were selected because they showed increased, decreased, or no change in GUS activity in response to various hormone applications. GUS expression in the roots of DML2 and DRM3 promoter lines treated with SA revealed upregulation of 1.51- and 2.45-fold compared with the corresponding mock-treated plants (Figure 8A). DML2 and DRM3 expression in these samples showed the same trend of upregulation showing 2.0- and 1.34-fold upregulation (Figure 8A). Similarly, the expression of both GUS and CMT3 showed slight upregulation in the auxin-treated roots of Pro:CMT3:GUS plants (Figure 8B). 
(A)

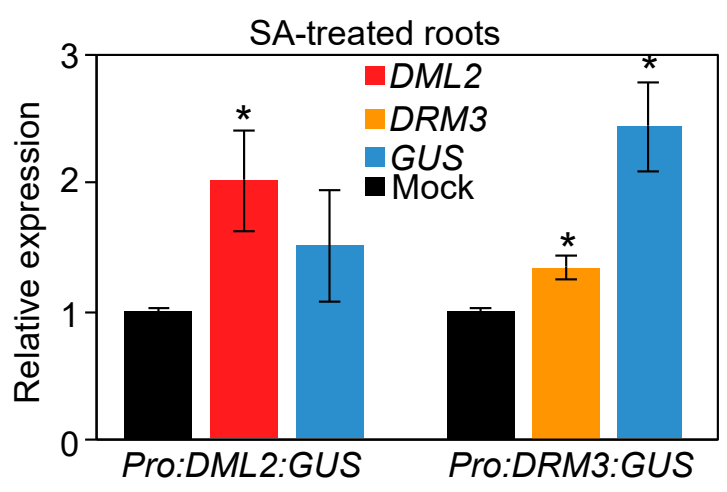

(C)

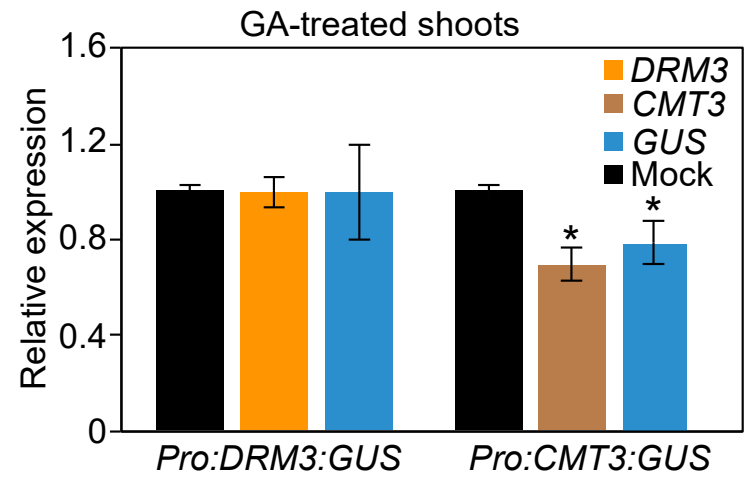

(B)

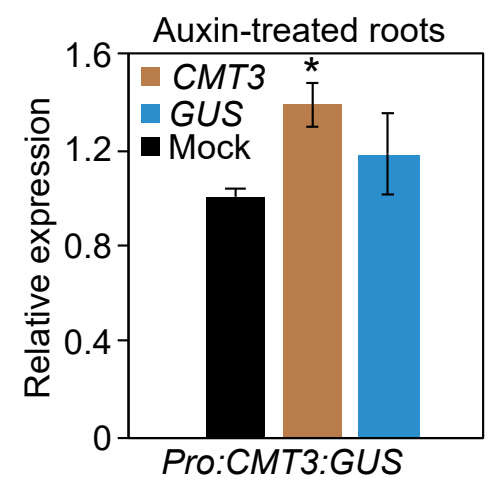

(D)

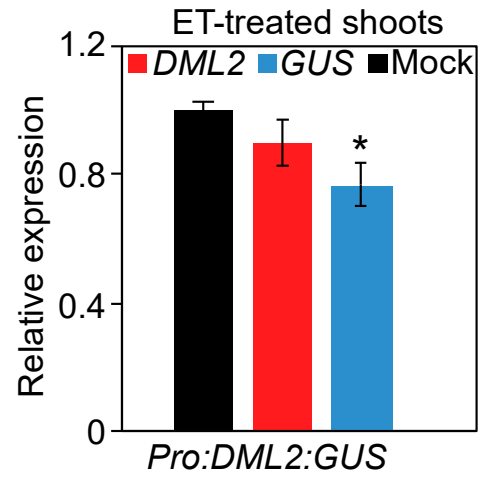

(E)

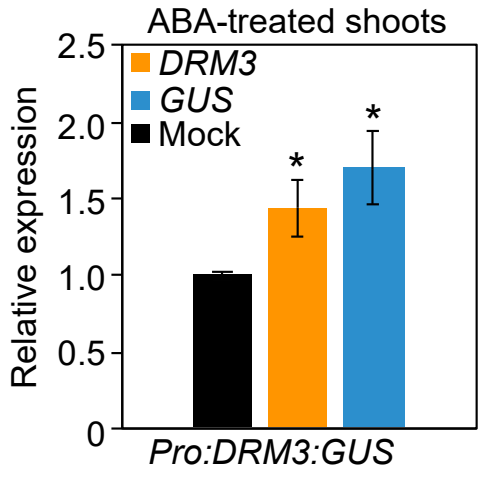

Figure 8. RT-qPCR quantification of GUS, DML2,DRM3, and CMT3 in the transgenic GUS reporter lines Pro:DML2:GUS, Pro:DRM3:GUS, and Pro:CMT3:GUS in response to various phytohormone treatments. (A): Expression levels of GUS, DML2, and DRM3 in the roots of two-week-old Pro:DML2:GUS or Pro:DRM3:GUS plants after SA treatment. (B): Expression levels of GUS and CMT3 in the roots of two-week-old Pro:CMT3:GUS plants after auxin treatment. (C): Expression levels of GUS, DRM3, and CMT3 in the shoots of two-week-old Pro:DRM3:GUS or Pro:CMT3:GUS plants after GA treatment. (D): Expression levels of GUS and DML2 in the shoots of two-week-old Pro:DML2:GUS plants after ET treatment. (E): Expression levels of GUS and DRM3 in the shoots of two-week-old Pro:DRM3:GUS plants after ABA treatment. Relative fold change values were calculated from three biological samples and represent expression in roots or shoots of hormone-treated transgenic plants relative to the corresponding tissues of mock-treated transgenic plants. Actin 8 and $P P 2 A A 3$ were used as internal controls to normalize gene expression values. Average CT (cycle threshold) values of Actin 8 and PP2AA3 were used to calculated ${ }^{\Delta \Delta} \mathrm{CT}$ values and gene expression levels. Asterisks indicate statistically significant differences between hormone-treated and mock-treated plants at $p<0.05$ according to $t$-test.

No notable change in the expression of GUS and DRM3 was detected in the GA-treated shoots of Pro:DRM3:GUS plants (Figure 8C). In contrast, both GUS and CMT3 showed comparable downregulation in GA treated shoots of Pro:CMT3:GUS plants in comparison with mock-treated shoots (Figure 8C). GUS and DML2 were similarly downregulated in the shoots of Pro:DML2:GUS plants treated with ET, showing 0.77- and 0.90-fold, relative to mock-treated shoots (Figure 8D). The expression levels of DRM3 and GUS were induced 1.43- and 1.70-fold, respectively, in the shoots of Pro:DRM3:GUS plants compared with the mock-treated shoots (Figure 8E). Together, the gene expression data confirm the accuracy of the transgenic GUS reporter lines in reflecting the transcriptional responses of DNA methylation and demethylation-related genes to various hormone treatments both in shoots and roots. 


\section{Discussion}

3.1. Promoter Activity of DNA Methylation and Demethylation-Related Genes in Various Plant Tissues and Organs

Our analysis revealed that DNA demethylases were generally more highly expressed at the mature end of the root, whereas genes involved in DNA methylation were more highly expressed in the newly grown regions of the roots (Figure 1). The spatial expression patterns of our reporter lines, together with the broader distinction between mature and newly grown parts of the root, are congruent with previous DNA methylation profiles reported in root tissues [69]. Our results also substantiate previous conclusions that DNA methylation is important for meristem differentiation and development of fast-growing tissues [60]. In addition, high expression levels of non-CG methyltransferases DRM2 and $D R M 3$ at the root tip (Figure 1B) is consistent with the findings that hypermethylation in root tips occurs primarily in the CHH context [69]. High activity of DRM2 promoter was also reported in root tips [61]. Our finding that several of the tested genes exhibit differential expression patterns in cotyledons, leaf primordia, and young and old leaves suggests a role of DNA methylation in shoot differentiation. This is consistent with the finding that DNA methylation plays a key role in cell identity [55].

Transition from juvenile to adult tissues and subsequent reproductive development is highly dependent on DNA methylation, alongside other regulatory factors and exogenous signals $[54,70,71]$. It has been shown that pre-anthesis buds are hypomethylated directly following the vegetative to reproductive transition, but the mechanism behind this loss of DNA methylation has not been determined [71]. The absence of DNA methyltransferase and demethylase expression in pre-anthesis buds (Figure 3) supports the notion that the hypomethylation of pre-anthesis floral organs is due to passive DNA demethylation. In contrast, reproductive tissues are hypermethylated during floral establishment and in subsequent stages of development [69,71]. Our results point to MET1, VIM1, DRM2, and DRM3 as key contributors to modulating the methylome status for the initial hypermethylation in early floral development (Figure 3A,B). Strong promoter activity of MET1 and $D R M 2$ was also reported in Arabidopsis floral organ [61]. In addition, VIM2 and DDM1 appear to play a role in later stages of flower development at the receptacle (Figure 3A,D). Our analysis also suggests that methylation status in various floral organs is under tight equilibrium through the activity of genes involved in DNA methylation and demethylation. For example, the high expression of $D M E$ in carpel, stamen, and pollen was accompanied by high expression of MET1, DRM2, and DRM3 (Figure 3A-C).

The strong promoter activity of several genes involved in DNA methylation and demethylation during various stages of seed development implies that the methylomes of developing seeds are established through coordinated functions of methyltransferases and demethylases. MET2b and MET3 were highly expressed during embryogenesis, despite their expression being barely detectable in other tissues (Figure 4A). MET1 homologs have been reported to express exclusively during embryogenesis [62,72]. This finding suggests that $M E T 2 b$ and MET3 acquired tissue-specific function to support the activity of MET1 in maintaining CG methylation during seed development. The embryo-specific expression of VIM1 suggests a coordinated function with MET1 to maintain CG methylation at specific loci, as suggested by Kim et al. [25].

The promoter activity of CMT1,CMT2, and DRM2 during embryogenesis is consistent with the programmed increase in $\mathrm{CHH}$ methylation during seed development reported in Arabidopsis and other plants [62,73-76]. This points to their implication in maintenance and de novo $\mathrm{CHH}$ methylation, respectively. In this context, it may be important to mention that a role of DRM2 in the maintenance of non-CG sites during embryogenesis can be expected. In addition, the expression of CMT2 is in line with the significant increase of global $\mathrm{CHH}$-context methylation within TEs located in pericentromeric region during seed development [76].

During embryogenesis and seed development, the endosperm tissues are hypomethylated, particularly at short TEs located nearby genes [73,77]. DME was established as 
the main demethylase responsible for genome-wide hypomethylation of Arabidopsis endosperm $[73,77,78]$. In addition to the role of $D M E$, our data suggest a key role for DML2 and DML3 in this process, and their role in establishing a hypomethylated endosperm merits further analysis (Figure 4C).

Tomato DML2-mediated DNA demethylation contributes to global hypomethylation during fruit ripening [48,79-81]. Our assays show that ROS1 and/or DME were expressed at silique internodes throughout development and that $D M E$ is highly expressed in the replum and septum (Figure 3C), suggesting their implication in silique maturation. Together with the expression of genes involved in DNA methylation in internodes, replum, stigma, and style (Figure $3 \mathrm{~A}, \mathrm{~B}$ ), our results suggest that DNA methylation and demethylation have a role in silique development and fruit ripening, as recently reported $[12,80,82,83]$.

\subsection{Phytohormone-Induced Changes in the Promoter Activity of DNA Methylation and Demethylation-Related Genes}

Our results provide evidence that phytohormones can alter DNA methylation dynamics in a specific and coordinated manner. In root tissues, we found that SA treatment inhibited the promoter activity of several genes but also activated the expression of CMT1, $D R M 3$, and DML2 (Figures 6 and 8A). The role of SA in root initiation and root growth [84] may be brought about in part through changes of DNA methylation pathways. SA-induced CMT1 expression in lateral roots implies a unique function of this enzyme in salicylic acid-mediated methylome changes in lateral roots (Figure 6B). Consistent with the role of SA in RAM patterning via auxin redistribution [85], our results point to a possible role of SA-dependent induction of CMT2 in this process, because CMT2 was the only gene expressed in the RAM of both AUX- and SA-treated roots (Figure 6B).

MET1 and the RdDM pathway have been identified to regulate active DNA demethylation through the methylation of a regulatory sequence in the ROS1 promoter [41]. Our GUS assays in roots and shoots support this regulation and implicate SA in this regulatory mechanism. In roots, the promoter activity of MET1, DRM2, and DRM3 in root tips, and ROS1 in root cap, was strongly repressed in response to SA treatment (Figure 6). Similarly, in shoots, SA treatment reduced or eliminated the expression of MET1, DRM2, DRM3, and ROS1 in older leaves and/or cotyledons (Figure 7). ABA may also be involved in this regulatory mechanism, particularly in younger leaves, as the expression of MET1 and ROS1 was reduced or eliminated in these tissues upon ABA application (Figure 7).

AUX, CK, ET and ABA treatments also impacted the promoter activity of certain DNA methylation and demethylation-related genes in various root tissues, suggesting that a hormone-linked methylome regulation mechanism may contribute to root growth and development. In many cases, phytohormone treatments resulted in an obvious impact on GUS expression in the shoots. Some genes showed similar responses to various hormone treatments, as in the case of DDM1, whose expression was inhibited in response to all hormone applications in shoots (Figure 7D). Other genes showed opposite responses to certain hormone treatments. For example, VIM2 was positively regulated by SA and GA treatments in older leaves, but its expression was strongly suppressed by ABA (Figure 7A). Interestingly, ROS1 expression is enhanced in response to GA and ET treatments, but repressed by CK (Figure 7C), suggesting that ROS1-mediated DNA demethylation can be modulated by phytohormone signaling. Additionally, some hormone applications can differentially influence the expression of gene family members. For instance, VIM1 was upregulated in leaves following ABA treatment, whereas VIM2 expression was almost completely abolished (Figure 7A). We also realized that hormone applications triggered tissue-specific expression patterns. In this context, we found that DRM3 was upregulated in younger leaves and downregulated in older leaves in response to SA treatment (Figure 7B). Additionally, MET1 expression is reduced following ABA treatment in shoots, but not in roots (Figures 6A and 7A), supporting previous gene expression data showing downregulation of $M E T 1$ in a concentration-dependent manner in response to ABA treatments [86]. Taken together, these findings suggest that hormone signaling may contribute to the dynamic changes of DNA methylation associated with tissues development. 


\section{Materials and Methods}

\subsection{Plant Materials and Growth Conditions}

All transgenic Arabidopsis lines were generated in the Col-0 ecotype background. Plants were gown in controlled growth chambers at $22{ }^{\circ} \mathrm{C}$ under long day conditions, $16 \mathrm{~h}$ of light $\left(75 \mu \mathrm{mol} \mathrm{m} \mathrm{m}^{-2} \mathrm{~s}^{-1}\right)$ and $8 \mathrm{~h}$ of dark.

\subsection{Generation of GUS Reporter Lines}

Promoter regions (up to $2 \mathrm{~kb}$ region upstream of the translation start codon ATG) were amplified from Col-0 genomic DNA using primers containing restriction enzyme sites (Supplementary Table S1). In some cases, the distance between the ATG and the $3^{\prime}$ untranslated region ( $\left.3^{\prime} \mathrm{UTR}\right)$ of the neighboring gene is less than $2 \mathrm{~kb}$. Therefore, we used the largest possible promoter region without including the $3^{\prime} U T R$ of the adjacent genes. Amplified PCR products were digested, purified, and cloned upstream of the $\beta$-glucuronidase (GUS) gene in the binary vector pBI101. Constructs were confirmed by sequencing before transferring into Agrobacterium tumefaciens (strain C58). The functionality of these constructs was validated using an A. tumefaciens infiltration assay [87]. Four-dayold seedlings were infiltrated with transformed A. tumefaciens for $36 \mathrm{~h}$, and seedlings were analyzed for GUS activity. Within 0.5 to $24 \mathrm{~h}$ of staining, colorimetric changes were visually observed for all infiltrated seedlings, confirming the function of all gene promoters.

Agrobacteria containing the binary vectors were then used to transform Arabidopsis (Col-0) using the floral dip method [88]. Transgenic T1 plants were screened on MS medium containing $50 \mathrm{mg} / \mathrm{L}$ kanamycin and $100 \mathrm{mg} / \mathrm{L}$ cefotaxime. Transgenic T1 lines were self-fertilized to generate T2 lines. T2 and subsequent generations were used for GUS assays.

\subsection{Histochemical Analysis of GUS Activity}

At least two independent transgenic lines were assayed for promoter activity, with at least six biological replicates. Seeds were grown in 12-well plates containing MS medium, and 14-day-old plants were assayed for GUS activity in root and shoot tissues. For GUS assays in reproductive tissues, transgenic plants were grown in soil at $22^{\circ} \mathrm{C}$ under long day conditions, and reproductive tissues, including buds, open flowers, emerging siliques, fully developed siliques, and mature siliques were assayed for GUS activity [89] using the X-Gluc substrate (5-bromo-4-chloro-3-indolyl-beta-D-glucuronic acid, cyclohexylammonium salt) (Rose Scientific, Cincinnati, OH, USA) at $37^{\circ} \mathrm{C}$ and checked every $30 \mathrm{~min}$ for colorimetric changes. The X-Gluc substrate was dissolved in $0.1 \mathrm{M}$ sodium phosphate buffer $(\mathrm{pH}=7)$ containing $20 \%$ methanol, $0.3 \%$ Triton $X-100,0.5 \mathrm{mM}$ potassium ferricyanide, and $0.5 \mathrm{mM}$ potassium ferrocyanide at a concentration of $1 \mathrm{mg} / \mathrm{mL}$. GUS staining time ranged from $30 \mathrm{~min}$ to $12 \mathrm{~h}$ based on the promoter activity. Once the staining was clearly visible, the reaction was terminated, to avoid overstaining, by replacing the GUS solution with $70 \%$ ethanol. The samples were then stored in ethanol at room temperature. Developing seeds were also precleared using 1:1 Acetic acid ethanol for 4-6 h and then cleared for 5 days using 75\% strength Hoyer's medium without gum arabic [90].

\subsection{Phytohormone Treatments}

Seeds of the transgenic GUS reporter lines were surface-sterilized and planted in 12-well plates containing MS medium in controlled growth chambers at $22{ }^{\circ} \mathrm{C}$ and $16 \mathrm{~h}$ light $/ 8 \mathrm{~h}$ dark cycle. At 13 days after planting, phytohormone and control treatments were applied to the transgenic seedlings. Excess liquids were removed using autoclaved filter papers. Phytohormone and control treatments were maintained for $24 \mathrm{~h}$ before determining GUS activity, both in roots and shoots, by adding GUS solution directly to the 12-well plates. The following phytohormones were used at the designated concentrations: $5 \mathrm{nM}$ Indole-3Acetic Acid (IAA, AUX), $15 \mathrm{nM}$ 6-Benzylaminopurine (BAP, CK), $75 \mu \mathrm{M}$ gibberellic acid (GA), $10 \mu \mathrm{M}$ 1-aminocyclopropane-1-carboxylic acid (ACC, ET), $10 \mu \mathrm{M}$ abscisic acid (ABA), and $2 \mathrm{mM}$ salicylic acid (SA), as previously described [91-95]. Stock solutions of these 
phytohormones were prepared in 100\% ethyl alcohol (IAA, ABA, and SA), $1 \mathrm{~N} \mathrm{NaOH}$ (BAP), or distilled water (GA and ACC). Mock treatments for control plants were carried out using distilled water (for GA and ACC treatments), $1.63 \times 10^{-9} \mathrm{~mol} / \mathrm{L}, 0.224 \mathrm{~mol} / \mathrm{L}$, and $0.08003 \mathrm{~mol} / \mathrm{L}$ ethyl alcohol for IAA, ABA, and SA treatments, respectively. Mocktreated control plants were included for each experiment and compared to treated plants. Phytohormone treatments were performed with two independent transgenic lines per construct.

\section{5. $R T-q P C R$ Analysis}

The expression levels of phytohormone marker genes for auxin (auxin response factor19 (ARF19), AT1G19220), cytokinin (arabidopsis response regulator7 (ARR7), AT1G19050), gibberellic acid (RGA-like 1 (RGL1)), ethylene (ethylene response2 (ETR2), AT3G23150), abscisic aid (MYB96, AT3G22830), and salicylic acid (pathogenesis-related gene1 (PR1), AT2G14610) were quantified in phytohormone-treated roots and shoots. The expression levels of VIM2, CMT3, DRM2, and DRM3 were measured in untreated roots and/or shoots of wild-type Col-0 plants. The expression levels of VIM1, CMT3, and DRM2 were also quantified in wildtype Col-0 plants in response to ABA, AUX, and GA applications, respectively. Additionally, the transgenic GUS reporter lines Pro:DML2:GUS, Pro:DRM2:GUS, and Pro:CMT3:GUS were used to quantify the expression of GUS and the corresponding endogenous genes in root or shoot tissues after various hormone treatment. Seeds of Arabidopsis wild-type ecotype Col-0 were planted in 12-well plates containing MS medium, and 13-day-old seedlings were subjected to various phytohormone and control treatments as described above. Twenty-four hours after the treatments, leaf and root tissues were collected in three biological samples and used for RNA extraction and RT-qPCR quantification. Total RNA was extracted using the Zymo Direct-zol RNA mimiprep kit (R2050) (Zymo Research, Irvine, CA, USA). RT-qPCR quantification was performed using $30 \mathrm{ng}$ of DNase-treated RNA per reaction with Verso SYBR green 1-step RT-qPCR (Thermo Scientific, Waltham, MA, USA), according to the manufacturer's instructions. RT-qPCR was performed in the QuantStudio 6 Flex Real-Time PCR System (Applied Biosystems, Foster City, CA, USA) using the following program: $50{ }^{\circ} \mathrm{C}$ for $15 \mathrm{~min}, 95^{\circ} \mathrm{C}$ for $15 \mathrm{~min}$ followed by 40 cycles of $95^{\circ} \mathrm{C}$ for $15 \mathrm{~s}, 60^{\circ} \mathrm{C}$ for $90 \mathrm{~s}$, and $72{ }^{\circ} \mathrm{C}$ for $30 \mathrm{~s}$. The PCR products were then subjected to $95{ }^{\circ} \mathrm{C}$ for $15 \mathrm{~s}$ and $60{ }^{\circ} \mathrm{C}$ for $75 \mathrm{~s}$, followed by a slow gradient from $60{ }^{\circ} \mathrm{C}$ to $95^{\circ} \mathrm{C}$ to generate the dissociation curves. Gene expression levels were normalized using two different reference genes: Actin8 (AT1G49240) and PROTEIN PHOSPHATASE 2A SUBUNIT A3 (PP2AA3, AT1G13320) [96]. Phytohormone-treated roots and shoots were then compared to mock-treated roots and shoots, respectively. Primer sequences for RT-qPCR assays are provided in Supplementary Table S1.

\subsection{Light Microscopy and Imaging}

Roots were imaged immediately because of their rapid degradation, even preserved in ethanol. Images of media-grown roots were captured from the bottom of the plate using an EVOS M7000 microscope. Shoots and reproductive tissues, on the other hand, were incubated in $70 \%$ ethanol for a few days to remove chlorophyll pigmentation, allowing GUS expression patterns to be clearly visible. These tissues were then imaged using a Zeiss Stemi 2000-CS dissecting microscope.

\subsection{RNA-Seq Data Analysis}

Gene expression data of DNA methylation and demethylation-related genes in roots, root tips, leaf, petiole, buds, open flower, and mature silique were downloaded from TraVA (Transcriptome Variation Analysis, http:/ / travadb.org/, accessed on 22 September 2020) [65]. Absolute RNA-seq read counts normalized by trimmed mean of M samples (TMM) were log10 transformed and used to generate a heatmap using the R package gplots and heatmap. 2 function. 
Supplementary Materials: The following are available online at https:/ / www.mdpi.com/article / 10.3390/ijms22189681/s1. Supplementary Figure S1: GUS staining assays of transgenic reporter lines showing absence of expression of the indicated DNA methylation and demethylation-related genes in roots (A), shoots (B), floral tissues and organ (C), and various stages of embryogenesis (D). Scale bar $=5 \mathrm{~mm}$, Supplementary Figure S2: Heatmap representation of gene expression levels of DNA methylation and demethylation-related genes across different tissues and organs, Supplementary Figure S3: RT-qPCR quantification of selected DNA methylation-related genes in 2-week-old wild-type Col-0 plants. A: Expression levels of VIM2, CMT3, and DRM3 in the roots of 2-week-old wild-type Col-0 plants. B. Expression levels of VIM2, CMT3, and DRM2 in the shoots of 2-week-old wild-type Col-0 plants. Relative fold change values were calculated from three biological samples and represent expression levels of CMT3, DRM2, or DRM3 relative to VIM2, which were set to 1 . Actin 8 and $P P 2 A A 3$ were used as internal control to normalize gene expression values. Average CT (cycle threshold) values of Actin 8 and PP2AA3 were used to calculated ${ }^{\triangle \Delta} \mathrm{CT}$ values and gene expression levels. Asterisks indicate statistically significant differences from the expression values of VIM2 at $p<0.05$ according to $t$-test, Supplementary Figure S4: GUS staining assays of transgenic reporter lines showing no changes in expression of the indicated DNA methylation-related genes in roots (A), or shoots (B) following treatment with (from left to right) auxin (AUX), cytokinin (CK), gibberellic acid (GA), ethylene (ET), abscisic acid (ABA), or salicylic acid (SA). Scale bar $=5 \mathrm{~mm}$, Supplementary Figure S5: RT-qPCR quantification of selected DNA methylation-related genes in two-week-old wild-type Col-0 plants in response to the indicated phytohormone treatments. A: Expression levels of VIM1 in the root tissues of two-week-old wild-type Col-0 plants after ABA application. B: Expression levels of CMT3 in the root tissues of two-week-old wild-type Col-0 plants after AUX application. C: Expression levels of DRM2 in shoots of two-week-old wild-type Col-0 plants after GA application. Relative fold change values were calculated from three biological samples and represent expression in roots or shoots of hormone-treated plants relative to the corresponding tissues of mock-treated plants. Actin 8 and $P P 2 A A 3$ were used as internal control to normalize gene expression values. The average CT (cycle threshold) values of Actin 8 and $P P 2 A A 3$ were used to calculated ${ }^{\triangle \Delta} \mathrm{CT}$ values and gene expression levels. Asterisks indicate statistically significant differences between hormone-treated and mock-treated plants at $p<0.05$ according to $t$-test, Supplementary Table S1: Gene identification numbers and primers used in this study, Supplementary Table S2: Summary description of changes in promoter activity of DNA methylation and demethylation-related genes in two-week-old roots in response to phytohormone treatments, Supplementary Table S3: Summary description of changes in promoter activity of DNA methylation and demethylationrelated genes in two-week-old shoots in response to phytohormone treatments.

Author Contributions: Conceptualization, T.H.; data curation, M.B.; formal analysis, M.B.; investigation, M.B. and K.C.; methodology, M.B.; supervision, T.H.; writing-original draft, M.B.; writing-review and editing, T.H. All authors have read and agreed to the published version of the manuscript.

Funding: This work was supported by funds from the University of Tennessee, Institute of Agriculture to the Hewezi Laboratory.

Institutional Review Board Statement: Not applicable.

Informed Consent Statement: Not applicable.

Data Availability Statement: Not applicable.

Acknowledgments: We thank Sarbottam Piya for help with qPCR, and Earnest Bernard at the University of Tennessee for providing access to microscope facility in his laboratory. This work was supported by funds from the University of Tennessee, Institute of Agriculture to the Hewezi laboratory.

Conflicts of Interest: The authors declare no conflict of interest.

\section{Abbreviations}

ABA Abscisic acid

AUX Auxin

CK Cytokinin 


$\begin{array}{ll}\text { ET } & \text { Ethylene } \\ \text { GA } & \text { Gibberellic acid } \\ \text { RdDM } & \text { RNA-directed DNA methylation } \\ \text { SA } & \text { Salicylic acid } \\ \text { RAM } & \text { Root apical meristem }\end{array}$

\section{References}

1. Henderson, I.R.; Jacobsen, S.E. Epigenetic inheritance in plants. Nature 2007, 447, 418-424. [CrossRef]

2. Fransz, P.F.; De Jong, J.H. Chromatin dynamics in plants. Curr. Opin. Plant Biol. 2002, 5, 560-567. [CrossRef]

3. Zilberman, D.; Gehring, M.; Tran, R.K.; Ballinger, T.; Henikoff, S. Genome-wide analysis of Arabidopsis thaliana DNA methylation uncovers an interdependence between methylation and transcription. Nat. Genet. 2007, 39, 61-69. [CrossRef]

4. Zhang, M.; Kimatu, J.N.; Xu, K.; Liu, B. DNA cytosine methylation in plant development. J Genet. Genom. 2010, 37, 1-12. [CrossRef]

5. Matzke, M.A.; Mosher, R.A. RNA-directed DNA methylation: An epigenetic pathway of increasing complexity. Nat. Genet. 2014, 15, 394-408. [CrossRef] [PubMed]

6. Du, J.; Johnson, L.M.; Jacobsen, S.E.; Patel, D.J. DNA methylation pathways and their crosstalk with histone methylation. Nat. Rev. Mol. Cell Biol. 2015, 16, 519-532. [CrossRef]

7. López Sánchez, A.; Stassen, J.H.; Furci, L.; Smith, L.M.; Ton, J. The role of DNA (de) methylation in immune responsiveness of Arabidopsis. Plant J. 2016, 88, 361-374. [CrossRef]

8. Hewezi, T.; Pantalone, V.; Bennett, M.; Stewart, C.N.; Burch-Smith, T.M. Phytopathogen-induced changes to plant methylomes. Plant Cell Rep. 2018, 37, 17-23. [CrossRef]

9. Hewezi, T. Epigenetic Mechanisms in Nematode-Plant Interactions. Annu. Rev. Phytopathol. 2020, 58, 119-138. [CrossRef]

10. Hewezi, T.; Lane, T.; Piya, S.; Rambani, A.; Rice, J.H.; Staton, M. Cyst nematode parasitism induces dynamic changes in the root epigenome. Plant Physiol. 2017, 174, 405-420. [CrossRef]

11. Rambani, A.; Pantalone, V.; Yang, S.; Rice, J.H.; Song, Q.; Mazarei, M.; Arelli, P.R.; Meksem, K.; Stewart, C.N.; Hewezi, T. Identification of introduced and stably inherited DNA methylation variants in soybean associated with soybean cyst nematode parasitism. New Phytol. 2020, 227, 168-184. [CrossRef] [PubMed]

12. Huang, H.; Liu, R.; Niu, Q.; Tang, K.; Zhang, B.; Zhang, H.; Chen, K.; Zhu, J.K.; Lang, Z. Global increase in DNA methylation during orange fruit development and ripening. Proc. Natl. Acad. Sci. USA 2019, 116, 1430-1436. [CrossRef]

13. Rambani, A.; Hu, Y.; Piya, S.; Long, M.; Rice, J.H.; Pantalone, V.; Hewezi, T. Identification of differentially methylated miRNA genes during compatible and incompatible interactions between soybean and soybean cyst nematode. Mol. Plant-Microbe Interact. 2020, 33, 1340-1352. [CrossRef] [PubMed]

14. Wang, X.T.; Hu, L.J.; Wang, X.F.; Li, N.; Xu, C.M.; Gong, L.; Liu, B. DNA methylation affects gene alternative splicing in plants: An example from rice. Mol. Plant 2016, 9, 305-307. [CrossRef]

15. Bewick, A.J.; Schmitz, R.J. Gene body DNA methylation in plants. Curr. Opin. Plant Biol. 2017, 36, 103-110. [CrossRef] [PubMed]

16. Niyikiza, D.; Piya, S.; Routray, P.; Miao, L.; Kim, W.S.; Burch-Smith, T.; Gill, T.; Sams, C.; Arelli, P.R.; Pantalone, V.; et al. Interactions of gene expression, alternative splicing, and DNA methylation in determining nodule identity. Plant J. 2020, 103, 1744-1766. [CrossRef]

17. Lister, R.; O’Malley, R.C.; Tonti-Filippini, J.; Gregory, B.D.; Berry, C.C.; Millar, A.H.; Ecker, J.R. Highly integrated single-base resolution maps of the epigenome in Arabidopsis. Cell 2008, 133, 523-536. [CrossRef] [PubMed]

18. Cao, X.; Jacobsen, S.E. Role of the Arabidopsis DRM methyltransferases in de novo DNA methylation and gene silencing. Curr. Biol. 2002, 12, 1138-1144. [CrossRef]

19. Cao, X.; Aufsatz, W.; Zilberman, D.; Mette, M.F.; Huang, M.S.; Matzke, M.; Jacobsen, S.E. Role of the DRM and CMT3 methyltransferases in RNA-directed DNA methylation. Curr. Biol. 2003, 13, 2212-2217. [CrossRef]

20. Henderson, I.R.; Deleris, A.; Wong, W.; Zhong, X.; Chin, H.G.; Horwitz, G.A.; Kelly, K.A.; Pradhan, S.; Jacobsen, S.E. The de novo cytosine methyltransferase DRM2 requires intact UBA domains and a catalytically mutated paralog DRM3 during RNA-directed DNA methylation in Arabidopsis thaliana. PLoS Genet. 2010, 6, e1001182. [CrossRef]

21. Saze, H.; Scheid, O.M.; Paszkowski, J. Maintenance of CpG methylation is essential for epigenetic inheritance during plant gametogenesis. Nat. Genet. 2003, 34, 65-69. [CrossRef] [PubMed]

22. Kankel, M.W.; Ramsey, D.E.; Stokes, T.L.; Flowers, S.K.; Haag, J.R.; Jeddeloh, J.A.; Riddle, N.C.; Verbsky, M.L.; Richards, E.J. Arabidopsis MET1 cytosine methyltransferase mutants. Genetics 2003, 163, 1109-1122. [CrossRef] [PubMed]

23. Quadrana, L.; Silveira, A.B.; Mayhew, G.F.; LeBlanc, C.; Martienssen, R.A.; Jeddeloh, J.A.; Colot, V. The Arabidopsis thaliana mobilome and its impact at the species level. eLife 2016, 5, e15716. [CrossRef]

24. Zemach, A.; Kim, M.Y.; Hsieh, P.H.; Coleman-Derr, D.; Eshed-Williams, L.; Thao, K.; Harmer, S.L.; Zilberman, D. The Arabidopsis nucleosome remodeler DDM1 allows DNA methyltransferases to access H1-containing heterochromatin. Cell 2013, 153, 193-205. [CrossRef] [PubMed]

25. Kim, J.; Kim, J.H.; Richards, E.J.; Chung, K.M.; Woo, H.R. Arabidopsis VIM proteins regulate epigentic silencing by modulating DNA methylation and histone modification in cooperation with MET1. Mol. Plant 2014, 7, 1470-1485. [CrossRef] [PubMed] 
26. Long, J.C.; Xia, A.A.; Liu, J.H.; Jing, J.L.; Wang, Y.Z.; Qi, C.Y.; He, Y. Decrease in DNA methylation 1 (DDM1) is required for the formation of $\mathrm{mCHH}$ islands in maize. J. Integr. Plant Biol. 2019, 61, 749-764. [CrossRef] [PubMed]

27. Stroud, H.; Do, T.; Du, J.; Zhong, X.; Feng, S.; Johnson, L.; Patel, D.J.; Jacobsen, S.E. Non-CG methylation patterns shape the epigenetic landscape in Arabidopsis. Nat. Struct. Biol. 2014, 21, 64. [CrossRef]

28. Stroud, H.; Greenberg, M.V.; Feng, S.; Bernatavichute, Y.V.; Jacobsen, S.E. Comprehensive analysis of silencing mutants reveals complex regulation of the Arabidopsis methylome. Cell 2013, 152, 352-364. [CrossRef] [PubMed]

29. Law, J.A.; Jacobsen, S.E. Establishing, maintaining and modifying DNA methylation patterns in plants and animals. Nat. Genet. 2010, 11, 204-220. [CrossRef]

30. Costa-Nunes, P.; Kim, J.Y.; Hong, E.; Pontes, O. The cytological and molecular role of domains rearranged methyltransferase3 in RNA-dependent DNA methylation of Arabidopsis thaliana. BMC Res. Notes 2014, 7, 721. [CrossRef]

31. Gong, Z.; Morales-Ruiz, T.; Ariza, R.R.; Roldán-Arjona, T.; David, L.; Zhu, J.K. ROS1, a repressor of transcriptional gene silencing in Arabidopsis, encodes a DNA glycosylase/lyase. Cell 2002, 111, 803-814. [CrossRef]

32. Penterman, J.; Uzawa, R.; Fischer, R.L. Genetic interactions between DNA demethylation and methylation in Arabidopsis. Plant Physiol. 2007, 145, 1549-1557. [CrossRef] [PubMed]

33. Penterman, J.; Zilberman, D.; Huh, J.H.; Ballinger, T.; Henikoff, S.; Fischer, R.L. DNA demethylation in the Arabidopsis genome. Proc. Natl. Acad. Sci. USA 2007, 104, 6752-6757. [CrossRef] [PubMed]

34. Zhu, J.; Kapoor, A.; Sridhar, V.V.; Agius, F.; Zhu, J.K. The DNA glycosylase/lyase ROS1 functions in pruning DNA methylation patterns in Arabidopsis. Curr. Biol. 2007, 17, 54-59. [CrossRef]

35. Ortega-Galisteo, A.P.; Morales-Ruiz, T.; Ariza, R.R.; Roldán-Arjona, T. Arabidopsis DEMETER-LIKE proteins DML2 and DML3 are required for appropriate distribution of DNA methylation marks. Plant Mol. Biol. 2008, 67, 671-681. [CrossRef]

36. Choi, Y.; Gehring, M.; Johnson, L.; Hannon, M.; Harada, J.J.; Goldberg, R.B.; Jacobsen, S.E.; Fischer, R.L. DEMETER, a DNA glycosylase domain protein, is required for endosperm gene imprinting and seed viability in Arabidopsis. Cell 2002, 110, 33-42. [CrossRef]

37. Agius, F.; Kapoor, A.; Zhu, J.K. Role of the Arabidopsis DNA glycosylase/lyase ROS1 in active DNA demethylation. Proc. Natl. Acad. Sci. USA 2006, 103, 11796-11801. [CrossRef]

38. Gehring, M.; Huh, J.H.; Hsieh, T.F.; Penterman, J.; Choi, Y.; Harada, J.J.; Goldberg, R.B.; Fischer, R.L. DEMETER DNA glycosylase establishes MEDEA polycomb gene self-imprinting by allele-specific demethylation. Cell 2006, 124, 495-506. [CrossRef]

39. Morales-Ruiz, T.; Ortega-Galisteo, A.P.; Ponferrada-Marín, M.I.; Martínez-Macías, M.I.; Ariza, R.R.; Roldán-Arjona, T. Demeter and repressor of silencing 1 encode 5-methylcytosine DNA glycosylases. Proc. Natl. Acad. Sci. USA 2006, 103, 6853-6858. [CrossRef]

40. Zhang, H.; Zhu, J.K. Active DNA demethylation in plants and animals. Cold Spring Harb. Symp. Quant. Biol. 2012, 77, 161-173. [CrossRef]

41. Lei, M.; Zhang, H.; Julian, R.; Tang, K.; Xie, S.; Zhu, J.K. Regulatory link between DNA methylation and active demethylation in Arabidopsis. Proc. Natl. Acad. Sci. USA 2015, 112, 3553-3557. [CrossRef]

42. Parrilla-Doblas, J.T.; Roldán-Arjona, T.; Ariza, R.R.; Córdoba-Cañero, D. Active DNA Demethylation in Plants. Int. J. Mol. Sci. 2019, 20, 4683. [CrossRef]

43. Dowen, R.H.; Pelizzola, M.; Schmitz, R.J.; Lister, R.; Dowen, J.M.; Nery, J.R.; Dixon, J.E.; Ecker, J.R. Widespread dynamic DNA methylation in response to biotic stress. Proc. Natl. Acad. Sci. USA 2012, 109, E2183-E2191. [CrossRef] [PubMed]

44. Le, T.N.; Schumann, U.; Smith, N.A.; Tiwari, S.; Au, P.C.K.; Zhu, Q.H.; Taylor, J.M.; Kazan, K.; Llewellyn, D.J.; Zhang, R.; et al. DNA demethylases target promoter transposable elements to positively regulate stress responsive genes in Arabidopsis. Genome Biol. 2014, 15, 458. [CrossRef] [PubMed]

45. Ramirez-Prado, J.S.; Abulfaraj, A.A.; Rayapuram, N.; Benhamed, M.; Hirt, H. Plant immunity: From signaling to epigenetic control of defense. Trends Plant Sci. 2018, 23, 833-844. [CrossRef] [PubMed]

46. Secco, D.; Wang, C.; Shou, H.; Schultz, M.D.; Chiarenza, S.; Nussaume, L.; Ecker, J.R.; Whelan, J.; Lister, R. Stress induced gene expression drives transient DNA methylation changes at adjacent repetitive elements. eLife 2015, 4, e09343. [CrossRef]

47. Zhang, B.; Tieman, D.M.; Jiao, C.; Xu, Y.; Chen, K.; Fei, Z.; Giovannoni, J.J.; Klee, H.J. Chilling-induced tomato flavor loss is associated with altered volatile synthesis and transient changes in DNA methylation. Proc. Natl. Acad. Sci. USA 2016, 113, 12580-12585. [CrossRef]

48. Guo, X.; Xie, Q.; Li, B.; Su, H. Molecular characterization and transcription analysis of DNA methyltransferase genes in tomato (Solanum lycopersicum). Genet. Mol. Biol. 2020, 43, e20180295. [CrossRef]

49. Santner, A.; Calderon-Villalobos, L.I.A.; Estelle, M. Plant hormones are versatile chemical regulators of plant growth. Nat. Chem. Biol. 2009, 5, 301-307. [CrossRef]

50. Berens, M.L.; Berry, H.M.; Mine, A.; Argueso, C.T.; Tsuda, K. Evolution of hormone signaling networks in plant defense. Annu. Rev. Phytopath. 2017, 55, 401-425. [CrossRef]

51. Blázquez, M.A.; Nelson, D.C.; Weijers, D. Evolution of plant hormone response pathways. Annu. Rev. Plant Biol. 2020, 71, 327-353. [CrossRef]

52. Waadt, R. Phytohormone signaling mechanisms and genetic methods for their modulation and detection. Curr. Opin. Plant Biol. 2020, 57, 31-40. [CrossRef]

53. Zhu, Y. The epigenetic involvement in plant hormone signaling. Chin. Sci. Bull. 2010, 55, 2198-2203. [CrossRef] 
54. Yamamuro, C.; Zhu, J.K.; Yang, Z. Epigenetic modifications and plant hormone action. Mol. Plant 2016, 9, 57-70. [CrossRef] [PubMed]

55. Maury, S.; Sow, M.D.; Le Gac, A.L.; Genitoni, J.; Lafon-Placette, C.; Mozgova, I. Phytohormone and Chromatin Crosstalk: The Missing Link for Developmental Plasticity? Front. Plant Sci. 2019, 10, 395. [CrossRef] [PubMed]

56. Xiao, K.; Chen, J.; He, Q.; Wang, Y.; Shen, H.; Sun, L. DNA methylation is involved in the regulation of pepper fruit ripening and interacts with phytohormones. J. Exp. Bot. 2020, 71, 1928-1942. [CrossRef] [PubMed]

57. Vanyushin, B.F. Enzymatic DNA methylation is an epigenetic control for genetic functions of the cell. Biochemistry 2005, 70, 488-499. [CrossRef]

58. Kooke, R.; Johannes, F.; Wardenaar, R.; Becker, F.; Etcheverry, M.; Colot, V.; Vreugdenhil, D.; Keurentjes, J.J. Epigenetic basis of morphological variation and phenotypic plasticity in Arabidopsis thaliana. Plant Cell 2015, 27, 337-348. [CrossRef]

59. Herman, J.J.; Sultan, S.E. DNA methylation mediates genetic variation for adaptive transgenerational plasticity. Proc. R. Soc. B 2016, 283, 20160988. [CrossRef]

60. Baubec, T.; Finke, A.; Scheid, O.M.; Pecinka, A. Meristem-specific expression of epigenetic regulators safeguards transposon silencing in Arabidopsis. EMBO Rep. 2014, 15, 446-452. [CrossRef] [PubMed]

61. Huang, J.; Wang, H.; Liang, W.; Xie, X.; Guo, G. Developmental expression of Arabidopsis methyltransferase genes MET1, DRM2, and CMT3. Mol. Biol. 2014, 48, 681-687. [CrossRef]

62. Jullien, P.E.; Susaki, D.; Yelagandula, R.; Higashiyama, T.; Berger, F. DNA methylation dynamics during sexual reproduction in Arabidopsis thaliana. Curr. Biol. 2012, 22, 1825-1830. [CrossRef] [PubMed]

63. Zhong, X.; Hale, C.J.; Nguyen, M.; Ausin, I.; Groth, M.; Hetzel, J.; Vashisht, A.A.; Henderson, I.R.; Wohlschlegel, J.A.; Jacobsen, S.E. Domains rearranged methyltransferase 3 controls DNA methylation and regulates RNA polymerase V transcript abundance in Arabidopsis. Proc. Natl. Acad. Sci. USA 2015, 112, 911-916. [CrossRef] [PubMed]

64. Roeder, A.H.; Yanofsky, M.F. Fruit development in Arabidopsis. In The Arabidopsis Book; Somerville, C., Meyerowitz, E., Eds.; American Society of Plant Biologists: Rockville, MD, USA, 2006. [CrossRef]

65. Klepikova, A.V.; Kasianov, A.S.; Gerasimov, E.S.; Logacheva, M.D.; Penin, A.A. A high resolution map of the Arabidopsis thaliana developmental transcriptome based on RNA-seq profiling. Plant J. 2016, 88, 1058-1070. [CrossRef]

66. Wen, C.K.; Chang, C. Arabidopsis RGL1 encodes a negative regulator of gibberellin responses. Plant Cell 2002, 14, 87-100. [CrossRef]

67. Nemhauser, J.L.; Hong, F.; Chory, J. Different plant hormones regulate similar processes through largely nonoverlapping transcriptional responses. Cell 2006, 126, 467-475. [CrossRef]

68. Mathur, V.; Tytgat, T.O.; Hordijk, C.A.; Harhangi, H.R.; Jansen, J.J.; Reddy, A.S.; Harvey, J.A.; Vet, L.E.; Van Dam, N.M. An ecogenomic analysis of herbivore-induced plant volatiles in Brassica juncea. Mol. Ecol. 2013, 22, 6179-6196. [CrossRef] [PubMed]

69. Bartels, A.; Han, Q.; Nair, P.; Stacey, L.; Gaynier, H.; Mosley, M.; Huang, Q.Q.; Pearson, J.K.; Hsieh, T.F.; An, Y.Q.C.; et al. Dynamic DNA methylation in plant growth and development. Int. J. Mol. Sci. 2018, 19, 2144. [CrossRef]

70. Yang, H.; Chang, F.; You, C.; Cui, J.; Zhu, G.; Wang, L.; Zheng, Y.; Qi, J.; Ma, H. Whole-genome DNA methylation patterns and complex associations with gene structure and expression during flower development in Arabidopsis. Plant J. 2015, 81, $268-281$. [CrossRef]

71. Campos-Rivero, G.; Osorio-Montalvo, P.; Sanchez-Borges, R.; Us-Camas, R.; Duarte-Ake, F.; De-la-Pena, C. Plant hormone signaling in flowering: An epigenetic point of view. Plant Physiol. 2017, 214, 16-27. [CrossRef] [PubMed]

72. Xu, W.; Yang, T.; Dong, X.; Li, D.Z.; Liu, A. Genomic DNA methylation analyses reveal the distinct profiles in castor bean seeds with persistent endosperms. Plant Physiol. 2016, 171, 1242-1258. [CrossRef] [PubMed]

73. Hsieh, T.F.; Ibarra, C.A.; Silva, P.; Zemach, A.; Eshed-Williams, L.; Fischer, R.L.; Zilberman, D. Genome-wide demethylation of Arabidopsis endosperm. Science 2009, 324, 1451-1454. [CrossRef] [PubMed]

74. Zemach, A.; Kim, M.Y.; Silva, P.; Rodrigues, J.A.; Dotson, B.; Brooks, M.D.; Zilberman, D. Local DNA hypomethylation activates genes in rice endosperm. Proc. Natl. Acad. Sci. USA 2010, 107, 18729-18734. [CrossRef] [PubMed]

75. Zhang, M.; Xie, S.; Dong, X.; Zhao, X.; Zeng, B.; Chen, J.; Yang, W.; Zhao, H.; Wang, G.; Chen, Z. Genome-wide high resolution parental-specific DNA and histone methylation maps uncover patterns of imprinting regulation in maize. Genome Res. 2014, 24, 167-176. [CrossRef]

76. Lin, J.Y.; Le, B.H.; Chen, M.; Henry, K.F.; Hur, J.; Hsieh, T.F.; Chen, P.Y.; Pelletier, J.M.; Pellegrini, M.; Fischer, R.L.; et al. Similarity between soybean and Arabidopsis seed methylomes and loss of non-CG methylation does not affect seed development. Proc. Natl. Acad. Sci. USA 2017, 114, E9730-E9739. [CrossRef] [PubMed]

77. Gehring, M.; Bubb, K.L.; Henikoff, S. Extensive demethylation of repetitive elements during seed development underlies gene imprinting. Science 2009, 324, 1447-1451. [CrossRef]

78. Gehring, M.; Satyaki, P.R. Endosperm and imprinting, inextricably linked. Plant Physiol. 2017, 173, 143-154. [CrossRef]

79. Zuo, J.; Wang, Y.; Zhu, B.; Luo, Y.; Wang, Q.; Gao, L. Comparative analysis of DNA methylation reveals specific regulations on ethylene pathway in tomato fruit. Genes 2018, 9, 266. [CrossRef]

80. Lang, Z.; Wang, Y.; Tang, K.; Tang, D.; Datsenka, T.; Cheng, J.; Zhang, Y.; Handa, A.K.; Zhu, J.K. Critical roles of DNA demethylation in the activation of ripening-induced genes and inhibition of ripening-repressed genes in tomato fruit. Proc. Natl. Acad. Sci. USA 2017, 114, E4511-E4519. [CrossRef] 
81. Liu, R.; How-Kit, A.; Stammitti, L.; Teyssier, E.; Rolin, D.; Mortain-Bertrand, A. A DEMETER-like DNA demethylase governs tomato fruit ripening. Proc. Natl. Acad. Sci. USA 2015, 112, 10804-10809. [CrossRef]

82. Xing, M.Q.; Zhang, Y.J.; Zhou, S.R.; Hu, W.Y.; Wu, X.T.; Ye, Y.J.; Wu, X.X.; Xiao, Y.P.; Li, X.; Xue, H.W. Global analysis reveals the crucial roles of DNA methylation during rice seed development. Plant Physiol. 2015, 168, 1417-1432. [CrossRef]

83. Kawakatsu, T.; Nery, J.R.; Castanon, R.; Ecker, J.R. Dynamic DNA methylation reconfiguration during seed development and germination. Genome Biol. 2017, 18, 171. [CrossRef]

84. Dempsey, D.M.A.; Klessig, D.F. How does the multifaceted plant hormone salicylic acid combat disease in plants and are similar mechanisms utilized in humans? BMC Biol. 2017, 15, 23. [CrossRef]

85. Pasternak, T.; Groot, E.P.; Kazantsev, F.V.; Teale, W.; Omelyanchuk, N.; Kovrizhnykh, V.; Palme, K.; Mironova, V.V. Salicylic acid affects root meristem patterning via auxin distribution in a concentration-dependent manner. Plant Physiol. 2019, 180, 1725-1739. [CrossRef]

86. Arıan, B.; Özden, S.; Turgut-Kara, N. DNA methylation related gene expression and morphophysiological response to abiotic stresses in Arabidopsis thaliana. Environ. Exp. Bot. 2018, 149, 17-26. [CrossRef]

87. Li, J.F.; Park, E.; von Arnim, A.G.; Nebenführ, A. The FAST technique: A simplified Agrobacterium-based transformation method for transient gene expression analysis in seedlings of Arabidopsis and other plant species. Plant Methods 2009, 5, 6. [CrossRef]

88. Clough, S.J.; Bent, A.F. Floral dip: A simplified method for Agrobacterium-mediated transformation of Arabidopsis thaliana. Plant J. 1998, 16, 735-743. [CrossRef] [PubMed]

89. Jefferson, R.A.; Kavanagh, T.A.; Bevan, M.W. GUS fusions: Beta-glucuronidase as a sensitive and versatile gene fusion marker in higher plants. EMBO J. 1987, 6, 3901-3907. [CrossRef]

90. Stangeland, B.; Salehian, Z. An improved clearing method for GUS assay in Arabidopsis endosperm and seeds. Plant Mol. Biol. Rep. 2002, 20, 107-114. [CrossRef]

91. Smalle, J.; Haegman, M.; Kurepa, J.; Van Montagu, M.; Van Der Straeten, D. Ethylene can stimulate Arabidopsis hypocotyl elongation in the light. Proc. Natl. Acad. Sci. USA 1997, 94, 2756-2761. [CrossRef]

92. Fujii, H.; Zhu, J.K. Arabidopsis mutant deficient in 3 abscisic acid-activated protein kinases reveals critical roles in growth, reproduction, and stress. Proc. Natl. Acad. Sci. USA 2009, 106, 8380-8385. [CrossRef] [PubMed]

93. Bidadi, H.; Yamaguchi, S.; Asahina, M.; Satoh, S. Effects of shoot-applied gibberellin/gibberellin-biosynthesis inhibitors on root growth and expression of gibberellin biosynthesis genes in Arabidopsis thaliana. Plant Root. 2010, 4, 4-11. [CrossRef]

94. Khokon, M.A.R.; Okuma, E.I.J.I.; Hossain, M.A.; Munemasa, S.; Uraji, M.; Nakamura, Y.; Mori, I.C.; Murata, Y. Involvement of extracellular oxidative burst in salicylic acid-induced stomatal closure in Arabidopsis. Plant Cell Environ. 2011, 34, 434-443. [CrossRef]

95. Piya, S.; Binder, B.M.; Hewezi, T. Canonical and noncanonical ethylene signaling pathways that regulate Arabidopsis susceptibility to the cyst nematode Heterodera schachtii. New Phytol. 2019, 221, 946-959. [CrossRef]

96. Piya, S.; Liu, J.; Burch-Smith, T.; Baum, T.J.; Hewezi, T. A role for Arabidopsis growth-regulating factors 1 and 3 in growth-stress antagonism. J. Exp. Bot. 2020, 71, 1402-1417. [CrossRef] 